\title{
NUMERICAL ANALYSIS FOR PUNCHING SHEAR RESISTANCE OF FLAT SLABS BY SHEAR HEADS
}

\author{
Badawy M. $\mathbf{M}^{1}$, Saafan $M^{2}$, Elwan S.K ${ }^{3}$, Elzeiny S.M ${ }^{4}$, Abdelrahman A.A. ${ }^{5}$ \\ ${ }^{1}$ Assistant Lecturer, Department of Civil Eng., The Higher Institute of Engineering, El Sherouk City, Cairo, Egypt \\ ${ }^{2}$ Associate Professor, Structural Engineering Department, Ain Shams University, Cairo, Egypt \\ ${ }^{3}$ Assistant Professor, Department of Civil Eng., The Higher Institute of Engineering, El Sherouk City, Cairo, Egypt \\ ${ }^{4}$ Professor of Reinforced Concrete Structures, Housing and Building National Research Center, Cairo, EGYPT \\ ${ }^{5}$ Professor of Reinforced Concrete Structures, Ain shams university, Cairo, Egypt
}

\begin{abstract}
This research presents a numerical analysis for punching shear resistance of flat slabs by shear heads. The results of thenumerical study demonstrated the efficiency of the proposed nonlinear finite element (NLFE) model by close matching the carrying capacity of the tested slab specimensin Ph.D.thesis ${ }^{[1]}$ and their comparative analyzed by the ANSYS program. The analytical program included representingten specimens withthree different column aspect ratio (1:1), (2:1) and (4:1) and two different lengths of steel shear head sections from column face $(L 1=1.75 \mathrm{~h}$ and $L 2=2.25 \mathrm{~h})$ where $(\mathrm{h})$ is flat slab thickness. The comparison revealed the accuracy of the analytical model in the representation of flat slabs whoever with or without steel shear head sections; including predicting the punching shear failure load, the behavior of these slabs, in addition to the crack pattern, strains of thebottom steel reinforcement and strains, shear stresses of shear heads. While the model is slightly satisfactory and reliable in predicting the punching failure load of flat slabs with and without steel shear heads. Both of ANSYS program and American code ACI 318-14 $4^{[2]}$ were used to investigate the punching shear resistance of flat slabs by shear heads. Based on the results of this analytical study, a proposed equation for calculating the punching shear capacity of flat slabs with shear heads was proposed. This equation can be utilized in the design of such flat slabs that connected with columns having the same aspect ratio.
\end{abstract}

Keywords: Punching Shear, Flat Slabs, Embedded Steel Shear Heads, Finite element modeling,ANSYS program, predicting punching Shear Failure Load.

\section{INTRODUCTION}

The finite element analysis (FEA) has wide applicability in structural engineering field, it can deal with models of various boundary conditions, unusual geometry, and different loading cases.

Nonlinear strain distribution along shear head length from column face must be taken in consideration to understand the behavior of flat slabs by shear heads. Using FEA in studying the effect of using embedded steel shear heads on the enhancement of punching shear capacity and behavior of reinforced concrete flat slabs.

The ACI $318-14^{[2]}$ is the only code in which predict the resisting punching force of flat slabs with shear heads. The ACI 318 code provisions for shear head reinforcement, which have been updated very little since 1977 (ACI Committee 318-1977) ${ }^{[3]}$ are used in conjunction with current and previous research findings (Corley and Hawkins $1968^{[4]}$; Hawkins1974; Hawkins and Corley $1974^{[5]}$ ) to develop the empirical strength model for the connections proposed in this study.
Previous researches concentrated upon studying the effect of using steel shear heads on the load capacity and the behavior of flat slabs such as; Corley and Hawkins, (1968) ${ }^{[4]}$ developed a detailed shear head system. This system uses structural steel sections welded together to form a grid which can then be placed around or through a columnas shown in Figure (1). Their study formed the basis of the shear head reinforcement design guidance in the American Code Institute design code ACI 318 (ACI-318 M,2005) ${ }^{[6]}$ and (ACI318-2011) ${ }^{[7]}$. A total of 21 specimens with the above shear head system (or without any shear head reinforcement) were tested and three typical failure modes (no shear head, over-reinforcing and under-reinforcing) were detected in their experimental study.

The failure surface of the slab without a shear head extended from the intersection of the column face and the compression face of the slab, towards the tension face of the slab with an inclined angle of about (20-30) degree to the horizontal until it reached the tension reinforcement level. 


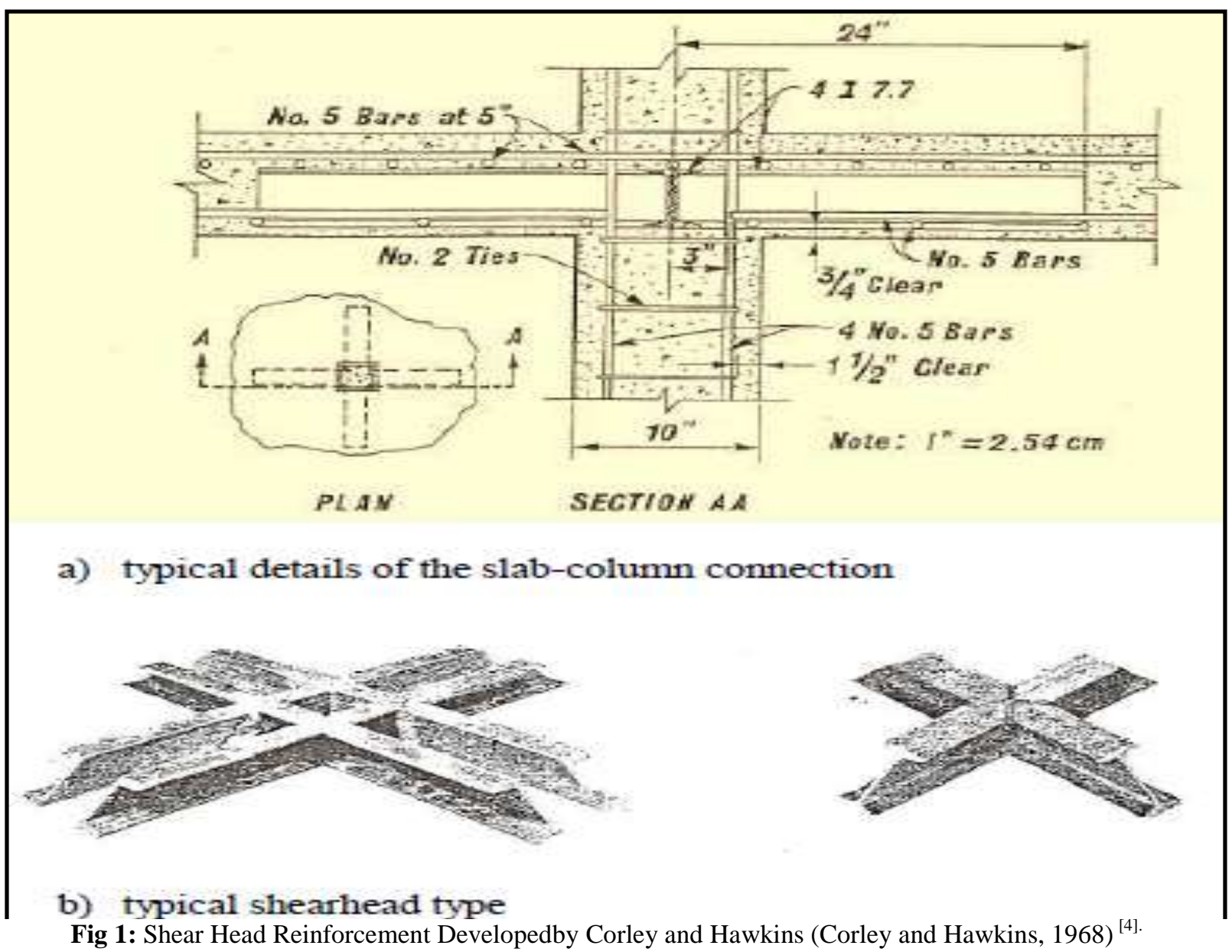

Jin-Won, Kim, etc. (2014) ${ }^{[8]}$. presented full-scale gravityload test results on ten concrete-filled tube (CFT) columnreinforced concrete $(\mathrm{RC})$ flat plate connections with shear heads. The CFT construction has many structural and constructional advantages over conventional steel and RC column construction. Use of RC flat plate systems in the basement and residential floors of tall buildings is often demanded to reduce story height and enable rapid construction. Combining CFT columns and flat plate flooring is expected to result in synergetic effects.

Use of shear heads is a viable option for shear reinforcing of flat plate connections with CFT columns, as the shear heads can simply be welded to the steel tube. This eliminates concerns of obstruction between the shear heads and column longitudinal reinforcement, which has been a major drawback of shear heads over the past decades in RC column construction. Additionally, the I-shaped steel shear head welded to the CFT column acts as a shear key and provides structural continuity between the slab and the column, where the interface shear transfer should be ensured.

The experimental program was devised to investigate the following design considerations: 1) length of the shear head arm; 2) concrete strength; 3) column aspect ratio; 4) the dimensional characteristics of the steel tube; and 5) slab thickness. The shear heads serve to increase the effective perimeter of the critical section for shear

According to ACI 318-11, Section 11.11.4 and R11.11.4.7 (ACI Committee 318-2011) ${ }^{[7]}$, nominal punching shear strength $V n$ is calculated as $0.33 \sqrt{ }\left(f_{c}{ }^{\prime}\right) \mathrm{MPa}\left(3.97 \sqrt{ }\left(f_{c}{ }^{\prime}\right)\right.$ psi) on assumed (outer) critical section, which crosses each shear head arm at $(3 / 4)(l v-(c 1 / 2))$ from the column face to the end of the shear head, as shown in Figure (2). Where $f_{c}^{\prime}$ is specifiedasa cylinder concrete strength, $l v$ is the distance between the end of the Shear head arm and the column center, and $c 1$ is the column dimension in the direction of the considered shear head. The shear head arm length was varied to investigate a minimum arm length that promotes the upper-cap punching shear strength of $0.58 \sqrt{ }\left(f_{c}^{\prime}\right) \mathrm{MPa}$ $\left(6.98 \sqrt{ }\left(f_{c}^{\prime}\right) \mathrm{psi}\right)$ on the (inner) critical section. The inner critical section is located at $d / 2$ from the column face, where $d$ is the slab effective depth. ACI $318-14^{[2]}$ does not explicitly define the required minimum length. It should be noted that in this paper, the critical sections at $d / 2$ and (3/4) $(l v-(c 1 / 2))$ from the column face are referred to as the inner and outer critical sections, respectively. 


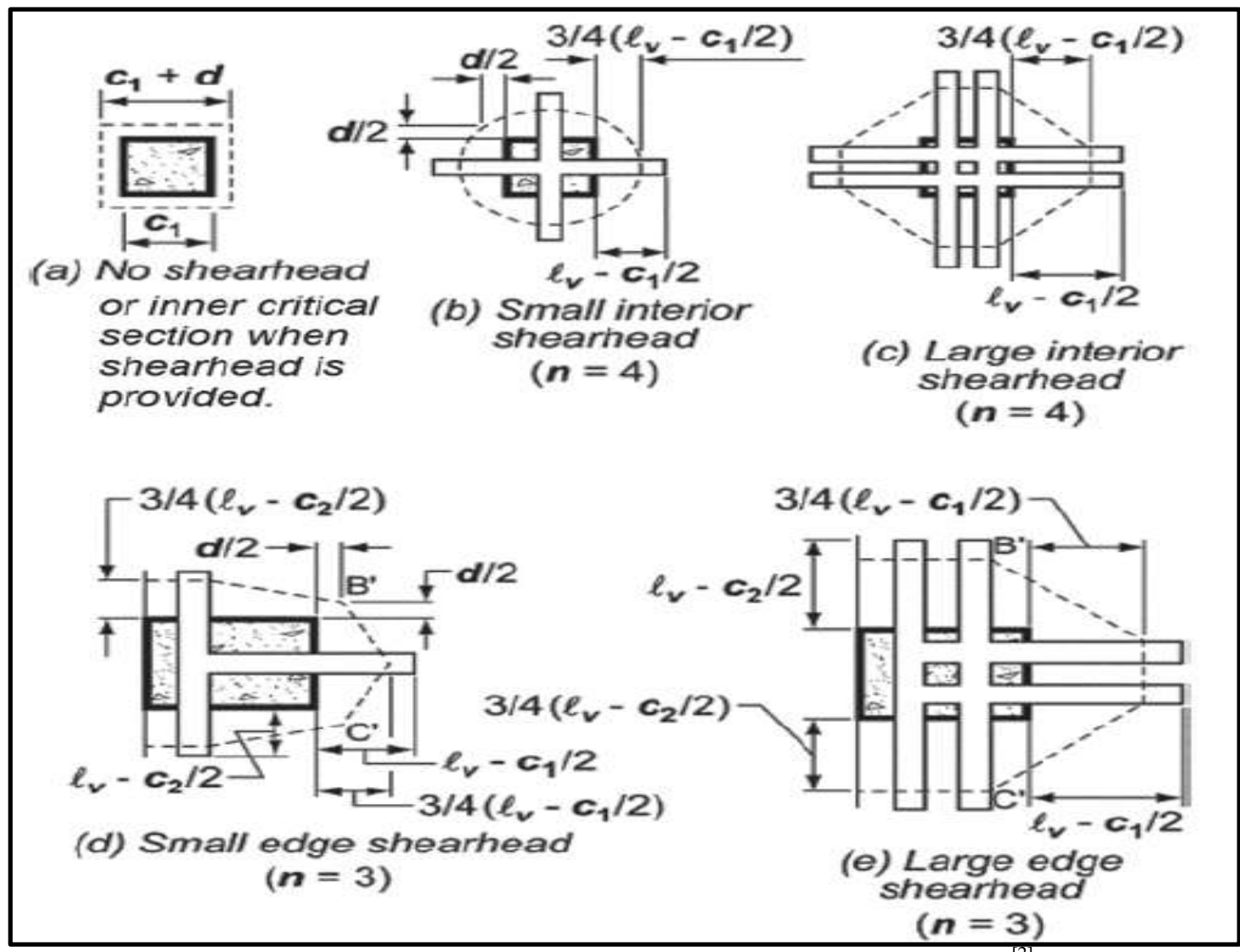

Fig 2: Critical Section Locations (Per ACI 318-14, Fig.R11.11.4.7) ${ }^{12}$

M.A. Eder, R.L. Volluma, A.Y. Elghazouli, T. Abdel-Fattah (2010) ${ }^{[9]}$ deals with the modelling of punching shear failure in reinforced concrete slabs using nonlinear finite element analysis. An analytical procedure is presented for simulating punching failure. The procedure is validated for a largescale reinforced concrete flat slab without shear reinforcement that failed in punching. A parametric analysis is carried out to determine the influence of the key parameters which govern the performance. The analytical procedure is then used to model the response of a large-scale hybrid reinforced concrete flat slab specimen tested at Imperial College London which failed in punching. The specimen incorporated a tubular steel column and an ACI 318 type structural steel shear head. The results of the analysis are used to gain fundamental insights into the contribution of the shear head to the shear resistance, and to assess the reliability of existing design recommendations for structural steel shear heads.

\section{MODELING OF REINFORCED CONCRETE}

\section{FLAT SLABS USING (ANSYS 12.0) [10]}

\subsection{Elements Types}

\subsubsection{Concrete Element}

SOLID65, an eight-node solid element, is used to model the concrete, which is special for 3Dmodelingforsolidconcreteelementswithorwithoutreinforcin grebar.The solid element haseight nodes with three degrees of freedom at each node-translations in the nodal $\mathrm{x}, \mathrm{y}$, and $\mathrm{z}$ directions. The element is capable of plastic deformation, cracking in three orthogonal directions, and crushing. Thegeometryandnode locations for this element type are shown in Figure (3) and Figure (4) shows finite element modeling of flat slabs which connected by different aspect ratio of columns. 


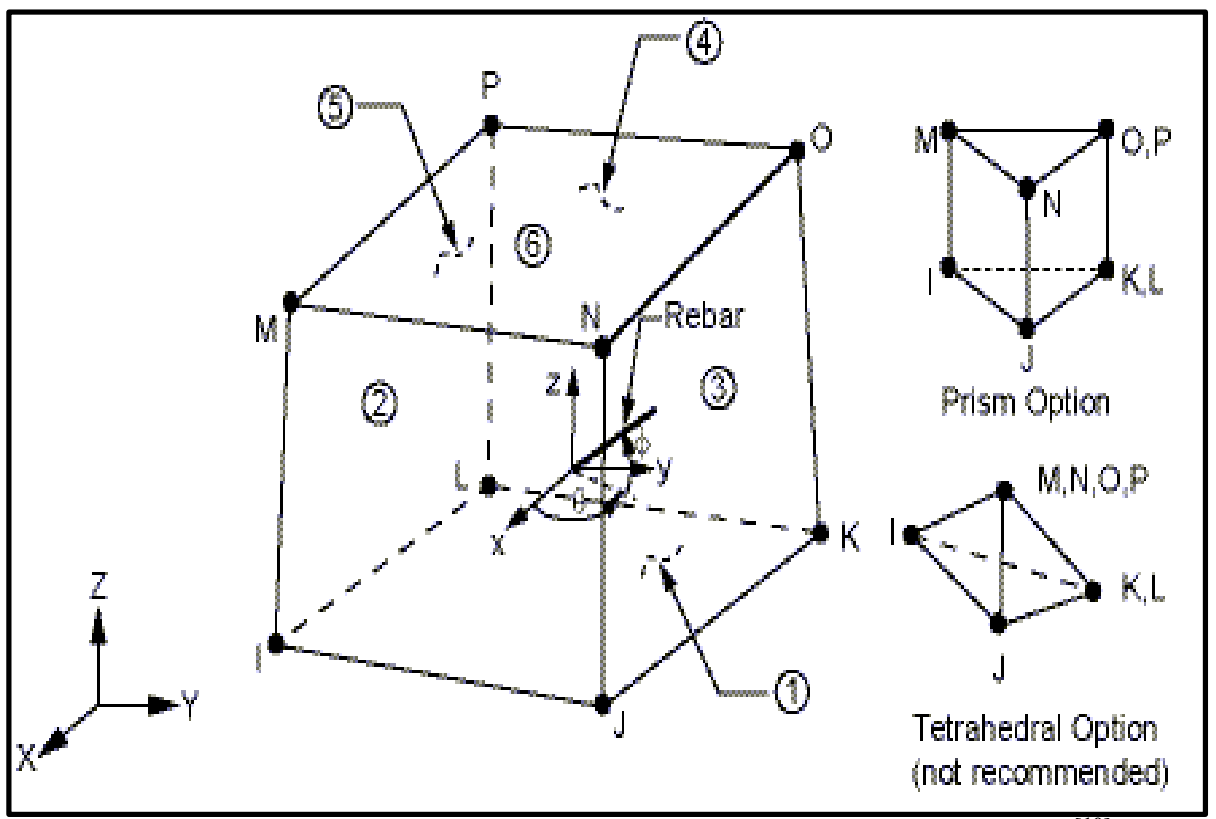

Fig 3: Solid65-3-D Reinforced Concrete Solid Element(ANSYS12.0) ${ }^{[10]}$.

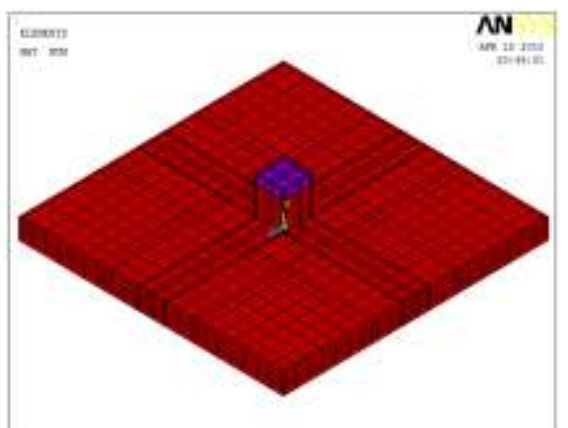

1-Modeling of Flat Slab Which Connected by Square Column (1:1).

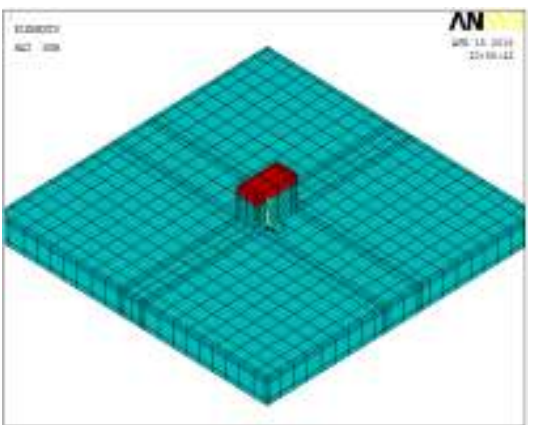

2-Modeling of Flat Slab Which Connected by Rectangle Column (2:1).

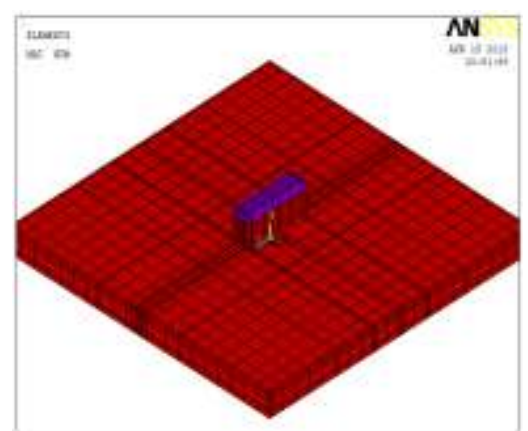

3-Modeling of Flat Slab Which Connected by Rectangle Column $(4: 1)$.

Fig 4: Finite Element Modeling of Flat Slabs Which Connected by Different Aspect Ratio of Columns Using Concrete Element (SOLID65) (ANSYS12.0) ${ }^{[10]}$.

\subsubsection{Steel Reinforcement Element}

Link8, For the discrete model,Link8 is an element used to model the steel reinforcement. Two nodes are required for this element. Each node has three degrees of freedom, translations in the nodal $\mathrm{x}, \mathrm{y}$, and $\mathrm{z}$ directions. The element is also capable of plastic deformation. The geometry and node locations for this element type is shown in Figure (5). Figure (6) shows modelling of bottom, top and column steel reinforcement with different aspect ratio.

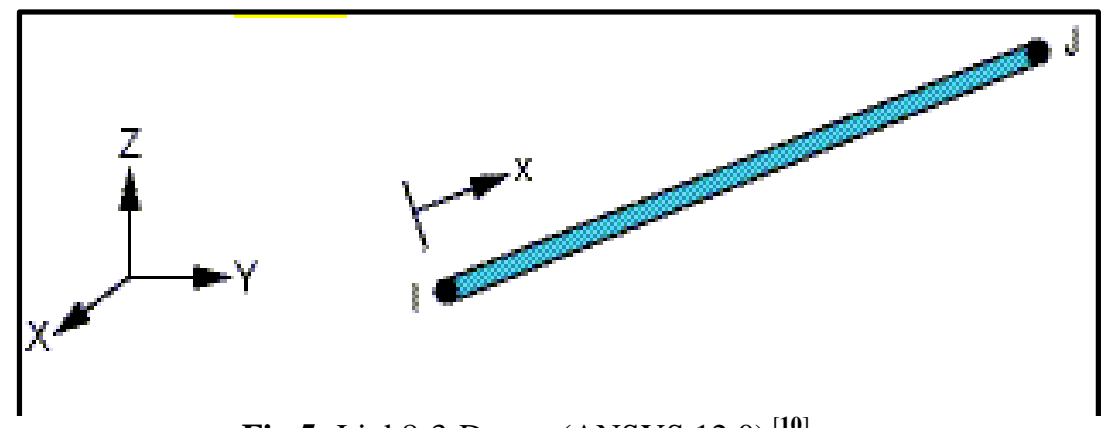

Fig 5: Link8-3-D spar (ANSYS 12.0) ${ }^{[10]}$. 


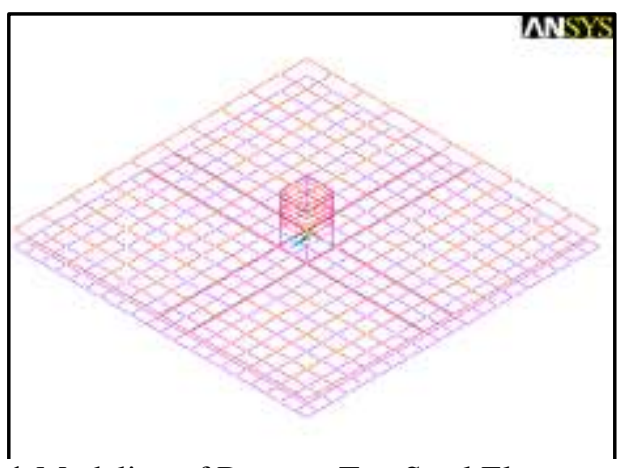

1-Modeling of Bottom, Top Steel Element and Square Column (1:1).

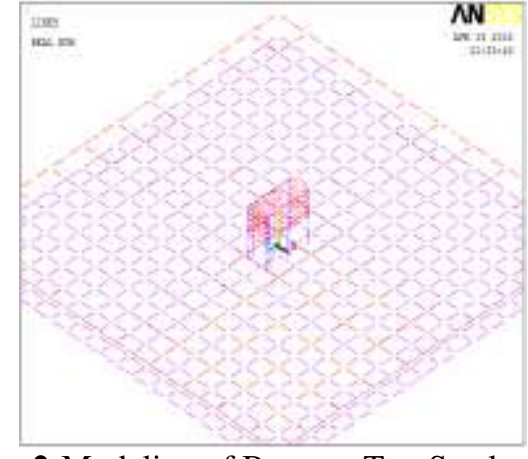

2-Modeling of Bottom, Top Steel Element and Rectangle Column $(2: 1)$

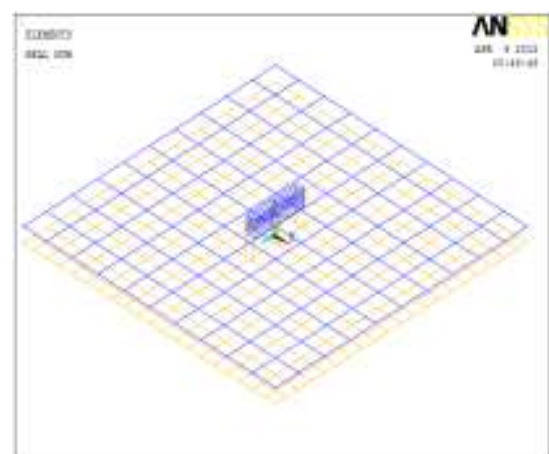

3-Modeling of Bottom, Top Steel Element and Rectangle Column (4:1).

Fig 6: Finite Element Modeling of Bottom, Top and Column Steel Reinforcement Using Steel Element (LINK8) (ANSYS12.0) [10]

\subsubsection{Steel Shear Head Element}

SHELL 181, is suitable for analyzing thin to moderate-thick element with six degrees of freedom at each node and valid for mimicking steel shear head sections. The geometry and node locations for this element type are shown in Figure (7).

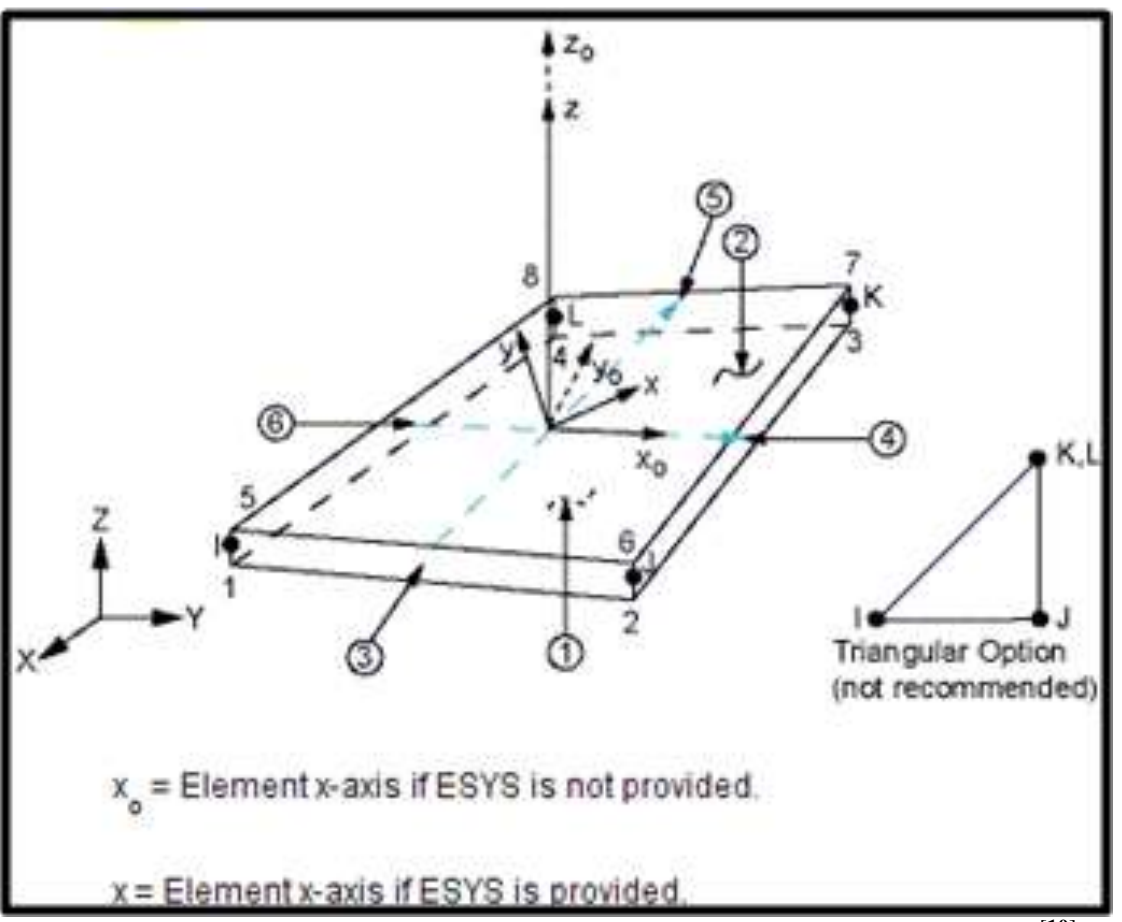

Fig 7: SHELL181 Used for Mimicking Steel Shear Head (ANSYS 12.0) ${ }^{[10]}$.

Figure (8) shows modelling of typical steel shear head section using (SHELL181) element in the finite element program (ANSYS12.0). Figure (9) shows modeling of steel shear heads in between bottom and top meshes for all slabs which connected by columns having different aspect ratio. 


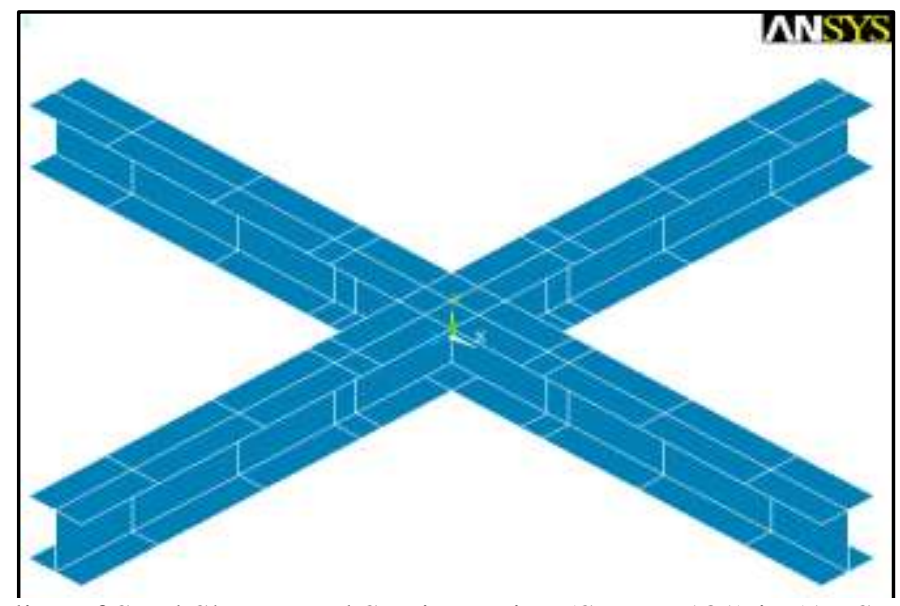

Fig 8: Modeling of Steel Shear Head Section Using (SHELL181) in (ANSYS 12.0) ${ }^{[10]}$.

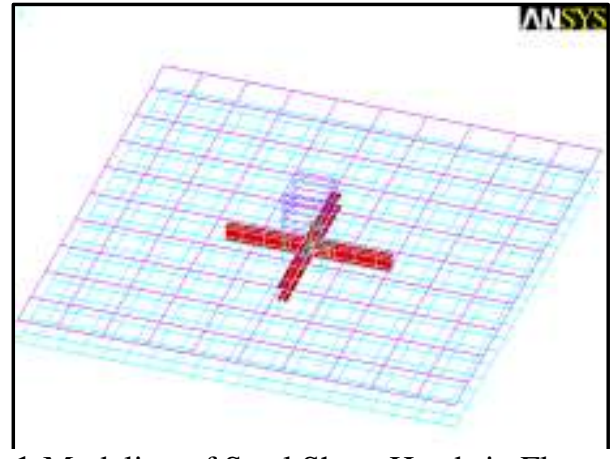

1-Modeling of Steel Shear Heads in Flat Slab which Connected By Square Column (1:1).

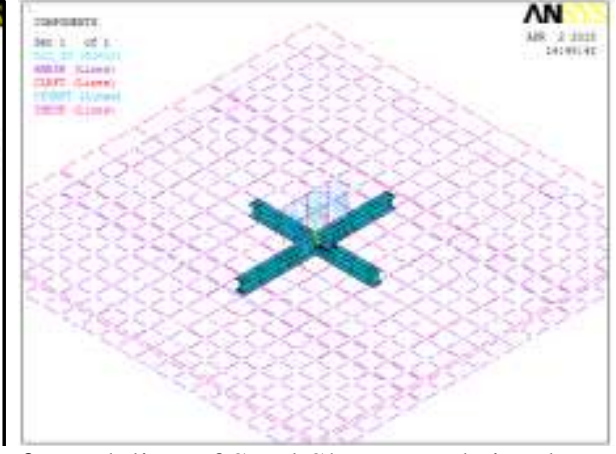

2-Modeling of Steel Shear Heads in Flat Slab which Connected By Rectangle Column (2:1).

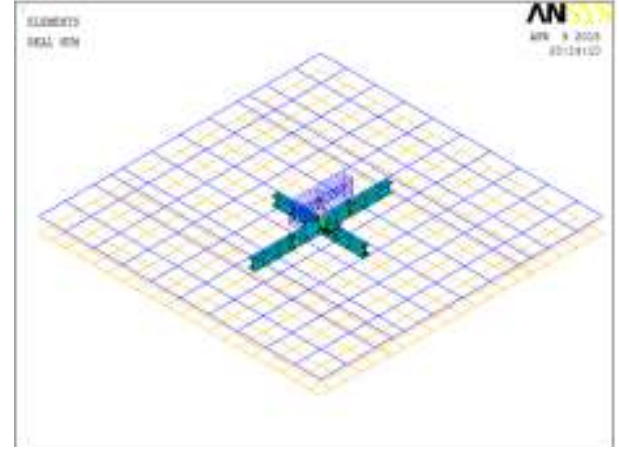

3-Modeling of Steel Shear Heads in Flat Slab which Connected By Rectangle Column (4:1).

Fig 9: Modeling of Embedded Steel Shear Head Section in Different Flat Slab Models Using (SHELL181).

\subsubsection{Lead Plates and Supports}

Solid45element used for steel plates at the supports for the column. This element has eight nodes with three degrees of freedom at each node translation in the nodal $\mathrm{x}, \mathrm{y}$, and $\mathrm{z}$ directions. The geometry and node locations for this element as shown in Figure(10).

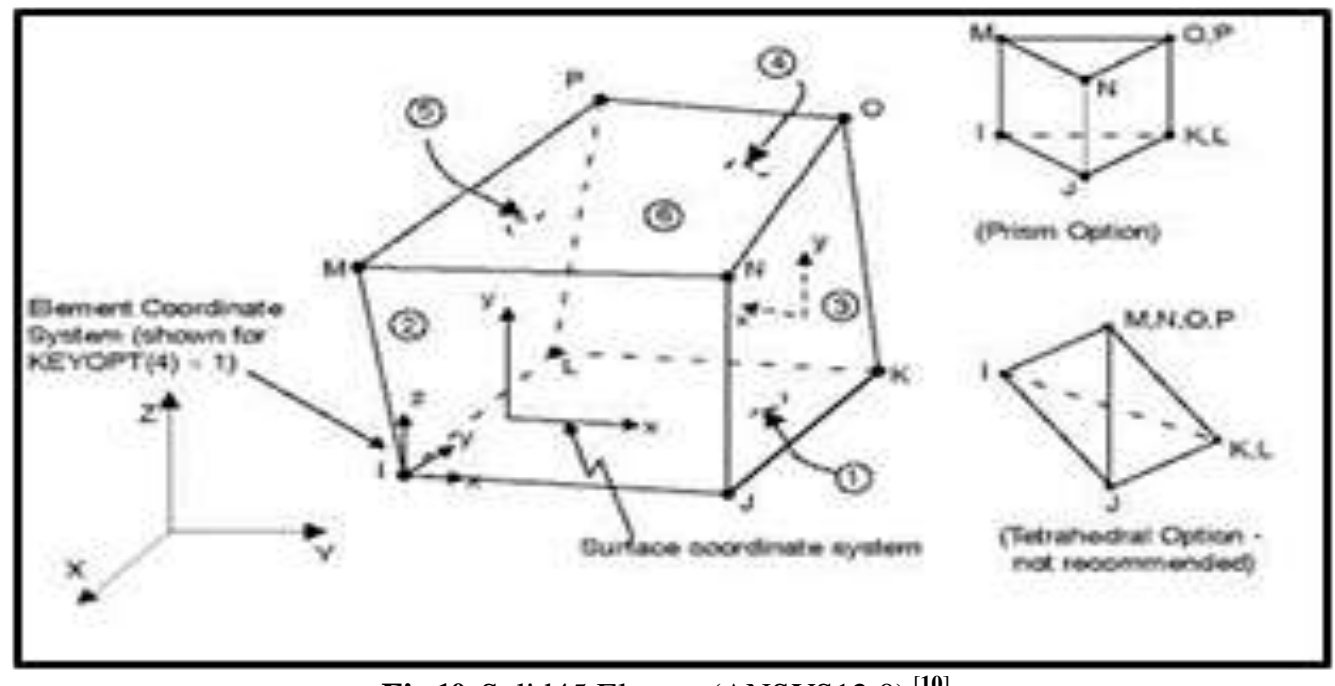

Fig 10: Solid45 Element(ANSYS12.0) ${ }^{[10]}$. 
To obtain a good simulation for the boundary conditions as they wererepresented in the practical test; four lines of nodes were constrained in $\mathrm{y}$ direction. By doingthis,theslab willbeallowedtorotateatthesupport but there are four quadrant nodes constrained in the two main direction (X and
Z) directions Thedisplacement control, $\Delta$, is concentrated inthe middle point of columnhead. Figure (11) shows supports condition of flat slab model(S-L1-2) in the finite element program (ANSYS 12.0) ${ }^{[\mathbf{1 0 ]}}$.

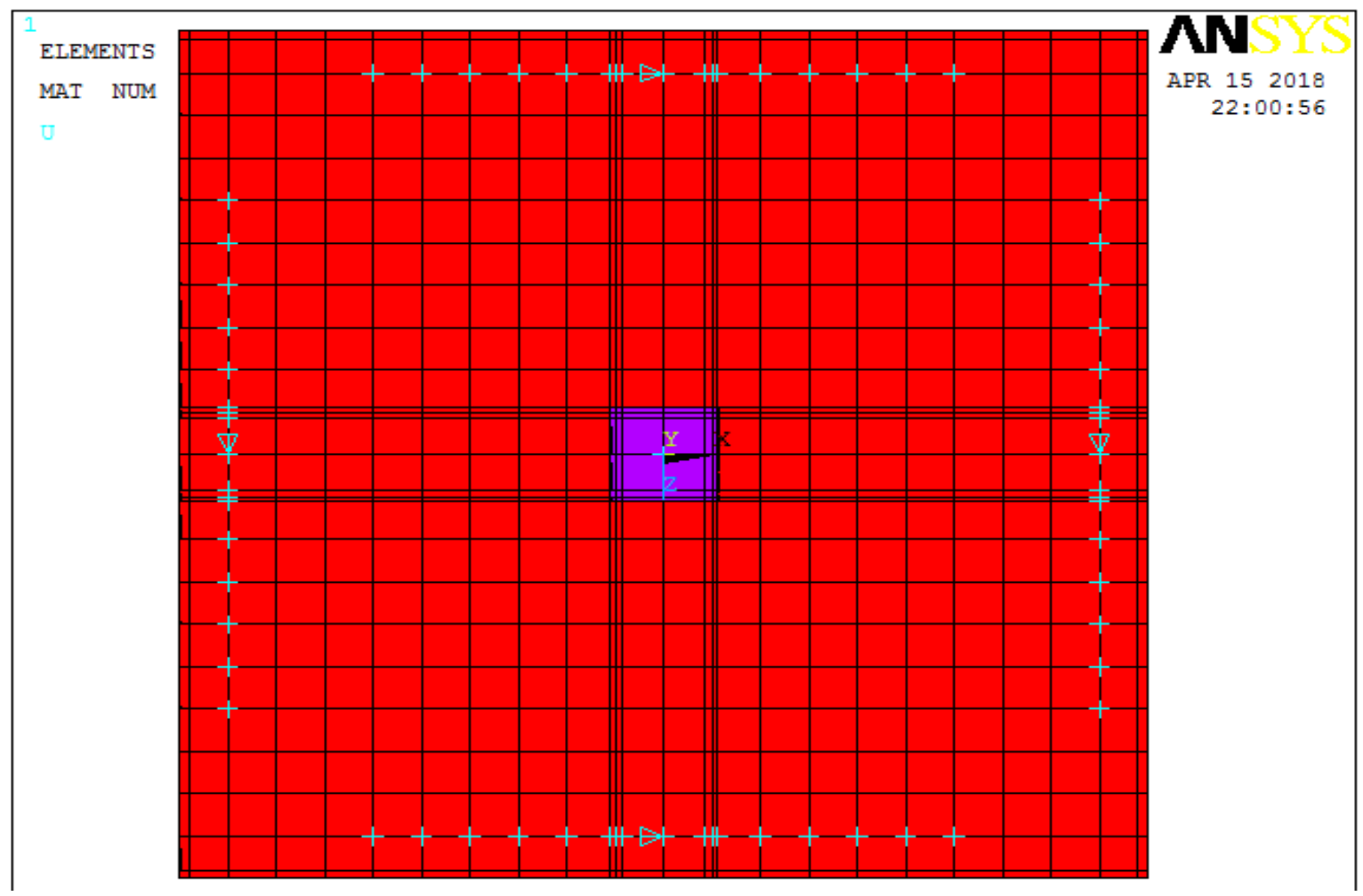

Fig 11: Supports Condition Used for All Flat Slab Models.

\subsection{Real Constant}

Element real constants are properties that depend on the element type,such as cross- sectional properties of a beam element. Not all element types require real constants, and different elements of the same type may have different real constant values and a single element type may reference several real constant sets.

\subsubsection{Concrete Element}

Real Constant set used for the Solid65 element. Values can be entered for Material Number, Volume Ratio, Orientation Angles, and Crushed Stiffness Factor (CSTF). The Crushed Stiffness Factor (CSTF): A value of (0.002) is entered to simulate the negative stiffness of the stress strain curve of concrete.

\subsubsection{Steel Reinforcement Element}

Real Constant set is defined for the Link8 element. Values for cross-sectional area in which equal to $78.5 \mathrm{~mm}^{2}$ and 254 $\mathrm{mm}^{2}$ for top and bottom steel reinforcement. initial strain is also entered. A value of zero is entered for the initial strain because there are no initial stresses in the reinforcement.

\subsubsection{Steel Shear Head Element}

Real Constant set is defined for SHELL181 element. Thickness values for web and flanges are entered by $5 \mathrm{~mm}$ for both elements at each required nodes for shell element.

\subsubsection{Lead Plates and Supports}

No real constant set exists for the Solid 45 element.

\subsection{Material Properties}

\subsubsection{Concrete Elements}

There are multiple parts of the material model for the concrete element as can be found in Table (1)., this material model refers to the Solid 65 element, used for all the concrete elements, and it is defined as linear isotropic for the elastic zone of the concrete, and multi-linear isotropic for the plastic zone of the concrete. The multi-linear isotropic material uses the von Mises failure criterion along with the William and Warnke (1974) ${ }^{[11]}$ model to define the failure of the concrete. The modulus of elasticity (EX) is defined, the poison's ratio (PRXY), and the compressive uniaxial stressstrain relationship for the concrete model. 
Implementation of the William and Warnke (1974) [11] material model in ANSYS requires that different constants. These 9 constants are:

1. Shear transfer coefficients for an open crack.

2. Shear transfer coefficient for a closed crack.

3. Uniaxial tensile cracking stress.

4. Uniaxial crushing stress (Positive).

5. Biaxial crushing stress (Positive).
6. Ambient hydrostatic stress state for use with constants 7 and 8.

7. Biaxial crushing stress (Positive) under the ambient hydrostatic stress state (constant 6).

8. Uniaxial crushing stress (Positive) under the ambient hydrostatic stress state (constant 6).

9. Stiffness multiplier for cracked tensile condition.

Table 1: Material Properties for The Concrete Element.

\begin{tabular}{|c|c|}
\hline \multicolumn{2}{|c|}{ Linear Isotropic } \\
\hline EX & 21053 \\
\hline PRXY & 0.18 \\
\hline \multicolumn{2}{|c|}{ Concrete } \\
\hline Coeff. of Open Shear & 0.30 \\
\hline Coeff. of Closed Shear & 0.90 \\
\hline Uniaxial Cracking Stress $\left(\mathrm{f}_{\mathrm{ctd}}\right)$ & 3.5 \\
\hline Uniaxial Crushing Stress $\left(\mathrm{f}_{\mathrm{cun}}\right)$ & 25 \\
\hline
\end{tabular}

\begin{tabular}{|c|c|c|}
\hline \multicolumn{3}{|c|}{ Multilinear Isotropic } \\
\hline Point & Stress & Strain \\
\hline Point1 & 6.00 & 0.000284 \\
\hline Point2 & 11.90 & 0.00060 \\
\hline Point3 & 15.90 & 0.00090 \\
\hline Point4 & 18.39 & 0.0012 \\
\hline Point5 & 19.64 & 0.0015 \\
\hline Point6 & 20 & 0.0018 \\
\hline Point7 & 25 & 0.0030 \\
\hline
\end{tabular}

The ANSYS program requires the uniaxial stress-strain relationship for concrete in compression. Numerical expression Equations 1,2and 3 were used along with equation 4 to construct the uniaxial compressive stress-strain curve for concrete in this study. Figure (12) shows the simplified compressive uniaxial stress-strain curve for concrete.

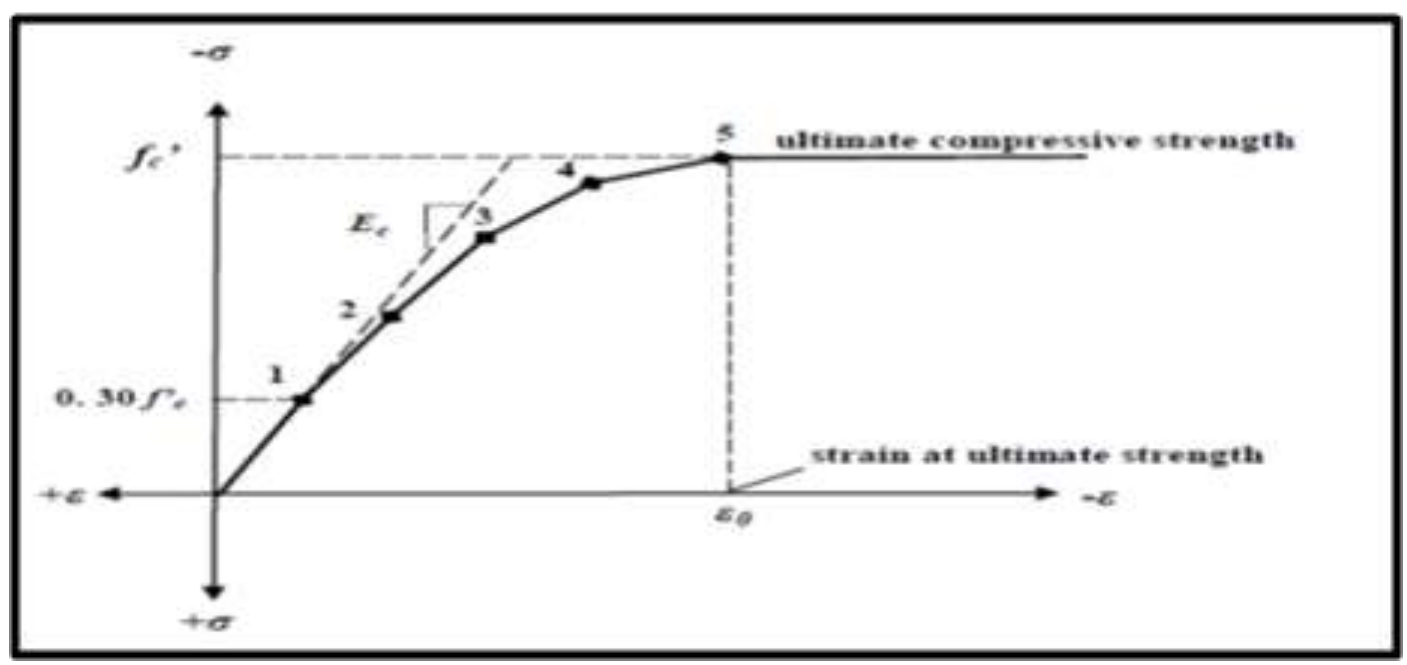

Fig 12: Simplified Compressive Uniaxial Stress-Strain Curve For Concrete.

$$
\begin{gathered}
f=\frac{E_{c} \zeta}{1+\left(\frac{\zeta}{\zeta_{o}}\right)^{2}} \\
\zeta_{o}=\frac{2 f_{c}^{\prime}}{E_{c}} \ldots .
\end{gathered}
$$

$$
E_{c}=\frac{f}{\zeta}
$$

Where:

$f=$ stress at any strain $\zeta, p s i$

$\zeta=$ strain at stress, $f$

$\zeta_{o}=$ strain at the ultimate compressive strength. 
The model is capable of predicting failure for concrete materials. Both cracking and crushing failure modes are accounted. The two inputs strength parameters ultimate uniaxial tensile and compressive strength are needed to define a failure surface for the concrete. Three-dimensional failure surface for concrete is shown in Figure (13).

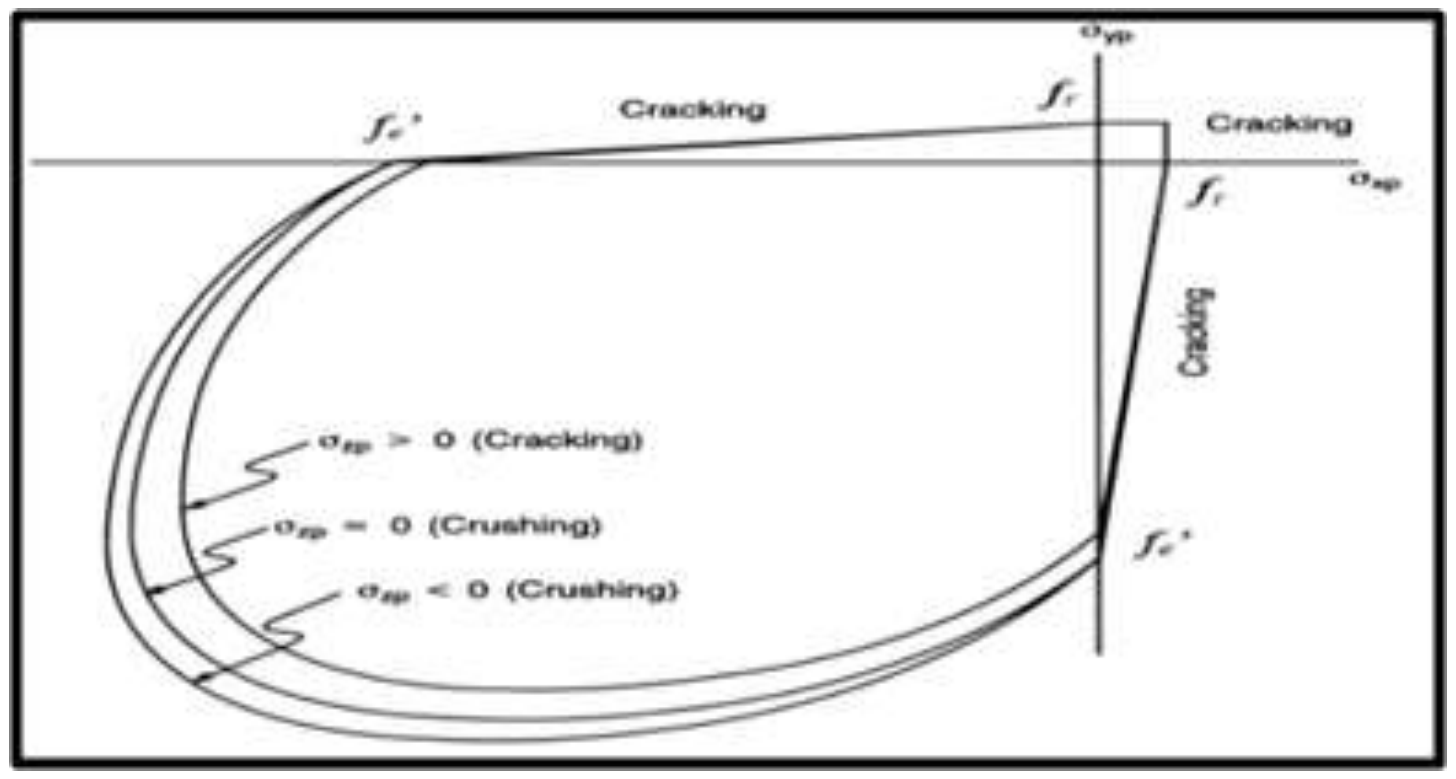

Fig 13: 3-D Failure Surface for Concrete(ANSYS12.0).

\subsubsection{Steel Reinforcement Element}

The steel for the finite element models was assumed to be an elastic-perfectly plastic material and identical in tension and compression. Figure (14) shows the stress-strain relationship used in this study.

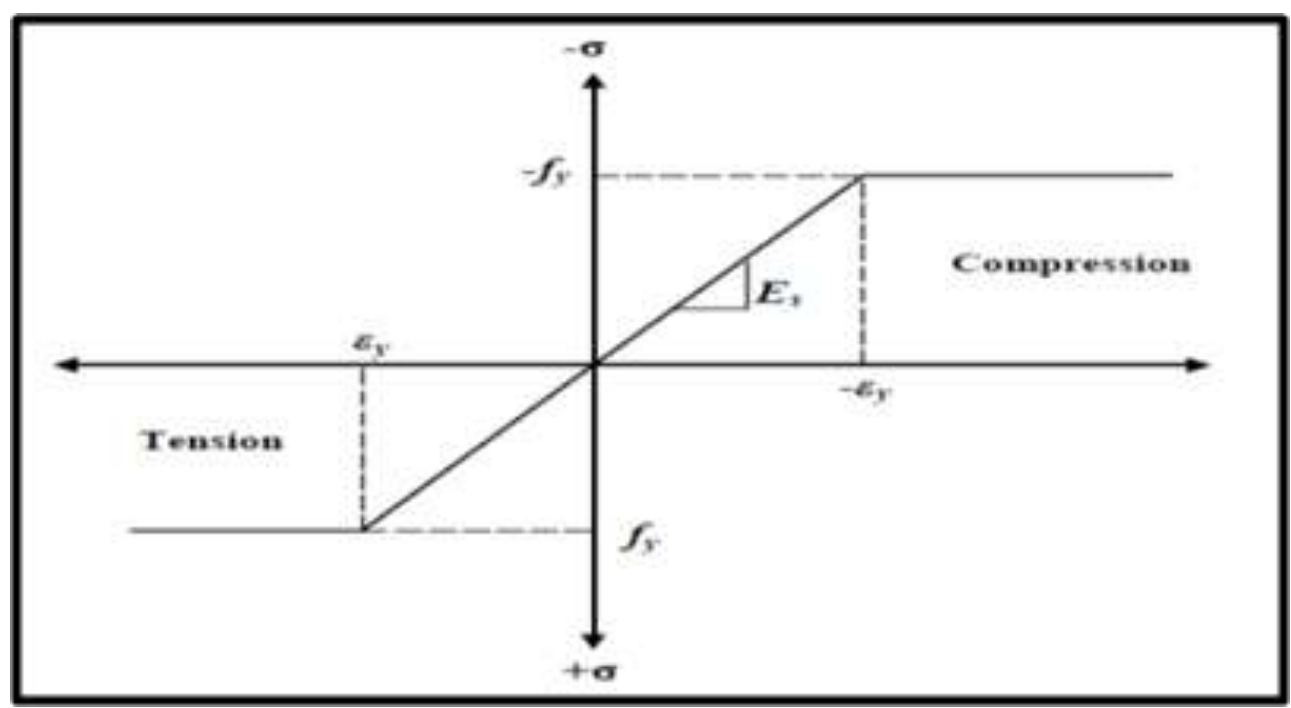

Fig 14: Stress-Strain Curve for Steel Reinforcement.

Parameters needed to define the material models can be found in Table (2). There are multiple parts of the material model for the Steel Reinforcement Element. This Material Model refers to the Link8 element, used for all the longitudinal steel reinforcement in the beam and it is defined as linear isotropic for the elastic zone of the steel and bilinear isotropic to define the second part of the curve asa straight line. Bilinear isotropic material is also based on the von Mises failure criteria. The bilinear model requires the yield stress $\left(f_{y}\right)$, aswell as the hardening modulus of the steel to be defined. Also the modulus of elasticity (EX), and the Poisson's ratio (PRXY).

Table 2: Material Properties for The Steel Reinforcement Element. 


\begin{tabular}{|c|c|c|c|c|c|}
\hline $\begin{array}{l}\text { Material Model } \\
\text { Number }\end{array}$ & $\begin{array}{l}\text { Element } \\
\text { Type }\end{array}$ & \multicolumn{4}{|c|}{ Material Properties } \\
\hline \multirow{3}{*}{$\begin{array}{l}2 \\
\text { (Tension RFT) }\end{array}$} & \multirow{3}{*}{ Link8 } & \multicolumn{2}{|c|}{ Linear Isotropic } & \multicolumn{2}{|l|}{ Bilinear Isotropic } \\
\hline & & EX & $2 \mathrm{e} 5$ & Yield Stress & 490 \\
\hline & & PRXY & 0.30 & Tangent Modulus & 6000 \\
\hline \multirow{3}{*}{$\begin{array}{l}3 \\
\text { (Compression RFT) }\end{array}$} & \multirow{3}{*}{ Link8 } & \multicolumn{2}{|c|}{ Linear Isotropic } & \multicolumn{2}{|l|}{ Bilinear Isotropic } \\
\hline & & $\mathrm{EX}$ & $2 \mathrm{e} 5$ & Yield Stress & 440 \\
\hline & & PRXY & 0.30 & Tangent Modulus & 6000 \\
\hline
\end{tabular}

\subsubsection{Steel Shear Head Element}

Table 3: Describes Material properties for the Steel Shear Head Section.

\begin{tabular}{|c|c|c|c|c|c|}
\hline $\begin{array}{l}\text { Material Model } \\
\text { Number }\end{array}$ & Element Type & \multicolumn{4}{|c|}{ Material Properties } \\
\hline \multirow{3}{*}{$\begin{array}{l}3 \\
\text { (Shear Heads) }\end{array}$} & \multirow{3}{*}{ SHELL181 } & \multicolumn{2}{|c|}{ Linear Isotropic } & \multicolumn{2}{|l|}{ Bilinear Isotropic } \\
\hline & & EX & $2 \mathrm{e} 5$ & Yield Stress & 300 \\
\hline & & PRXY & 0.30 & Tangent Modulus & 2000 \\
\hline
\end{tabular}

\subsubsection{Lead Plates and Supports}

This Material Model refers to the Solid45 element can be defined in Table (4). The Solid45 element used for the steel plates at loading points, and supports on the slab. Therefore, this element is modeled asa linear isotropic elementwitha modulus of elasticity for the steel (Es), and poison's ratio (PRXY).

Table 4: Material Properties for the Lead Plates and Supports Element.

\begin{tabular}{|l|l|l|l|}
\hline $\begin{array}{l}\text { Material Model } \\
\text { Number }\end{array}$ & Element Type & \multicolumn{2}{|l|}{ Material Properties } \\
\hline \multirow{3}{*}{4} & \multirow{3}{*}{ Solid45 } & Linear Isotropic \\
\cline { 3 - 4 } & & EX & $2 \mathrm{e} 5$ \\
\cline { 3 - 4 } & & PRXY & 0.30 \\
\hline
\end{tabular}

\section{VERIFICATION OF EXPERIMENTAL FLAT}

\section{SLAB TESTED SPECIMENS BY FINITE ELEMENT PROGRAM (ANSYS 12.0)}

\subsection{Specimens Details}

The experimental study was designed in Ph.D.thesis ${ }^{[1]}$ to observe the effect of changing column aspect ratio and length of steel shear head from column face on punching shear capacity and behavior of flat slabs.

All tested flat slabs with overall thickness " $h$ " equal to 150 $\mathrm{mm}$ and span equal $2000 \mathrm{~mm}$ in both directions with clear spans between supported beams equal to $1800 \mathrm{x} 1800 \mathrm{~mm}$. A total of seven slabs with square and rectangle column heads, were tested under punching shear loading. The clear concrete cover used was $10 \mathrm{~mm}$ to the bottom face of all test specimens.

All slabs were reinforced with bottom longitudinal steel bars mesh $1818 @ 100 \mathrm{~mm}$ and top mesh with \$10@200mm. All columns were reinforced with four longitudinal steel bars
Ф18 and confined with $\Phi 10 @ 100 \mathrm{~mm}$ bars as transverse reinforcements.

Several variables such as column aspect ratio, length of shear head arm from column face shallbe taken into consideration. Research program planwas divided in three groups.Table (5) summarizes the general description of the tested specimens.

The first group deals with testing three specimens of flat slabs connected with square columns, one specimen without any shear head as a control specimen and the other two specimens reinforced by steel shear head sections which have lengths equal to $1.75 \mathrm{~h}$ and $2.25 \mathrm{~h}$, respectively from column face. Figure (15) shows installed (LVDTs) and strain gauges in lower main reinforcement mesh for control flat slab specimen which connected by square columns. Figure (16) shows typical steel shear head between bottom and top steel reinforcement for specimens in which connected by square columns. Figure (17) shows locations and configuration of strain gauges in web and flanges of steel shear head sections.

The second group deals with three specimens of flat slabs connected with rectangular columns which have a column 
aspect ratio $(2: 1)$ and a column dimensions $(150 * 300)$ mm.one specimen without any shear head reinforcement as a control specimen.Figure (18) shows installed (LVDTs) and strain gauges in lower main reinforcement mesh for control flat slab specimen which connected by rectangle column have aspect ratio (2:1). two specimens reinforced by steel shear head sections which have a length equal to $1.75 \mathrm{~h}$ with cut end at angles 90. the last one, shear head length equal to $2.25 \mathrm{~h}$, to evaluate the effect of increasing shear head length. Figure (19)shows typical steel shear head between bottom and top steel reinforcement for specimens in which connected by rectangle column with aspect ratio (2:1).

The third group deals with two specimens of flat slabs connected with rectangular columns. One specimen without any shear head reinforcement as a control specimen with column aspect ratio (4:1) having column dimensions
(110*440) mm. Figure (20) shows installed (LVDTs) and strain gauges in lower main reinforcement mesh for control flat slab specimen which connected by rectangle column have aspect ratio (4:1). The other specimen reinforced by steel shear head sections which have a length equal to $(1.75 \mathrm{~h})$ with cut end at angle 90 degrees. These specimens have been studied to evaluate the effect of increasing column aspect ratio.Figure (21)shows typical steel shear head between bottom and top steel reinforcement for specimen in which connected by rectangle column with aspect ratio (2:1).

The same installed LVDTs and strain gauges of flat slab model which connected by rectangle column with aspect ratio $(2: 1)$ are the same ratios in whichused for flat slab specimens in which connected by column with aspect ratio $(4: 1)$

Table 5: General Description of Tested Flat Slab Specimens.

\begin{tabular}{|c|c|c|c|c|c|c|}
\hline Group & Specimen & $\begin{array}{l}\text { Actual } \\
\text { Comp. } \\
\text { Strength } \\
\left(f_{c u}\right) M P a\end{array}$ & $\begin{array}{l}\text { Colum } \\
n \\
\text { Aspect } \\
\text { Ratio }\end{array}$ & $\begin{array}{l}\text { Column } \\
\text { Dimension } \\
s\end{array}$ & $\begin{array}{l}\text { Shear } \\
\text { Head } \\
\text { Length }\end{array}$ & Remarks \\
\hline \multirow{3}{*}{ Group (1) } & $S C$ & 25 & 1 & $220 * 220$ & without & Control specimen \\
\hline & $S-L 1-2$ & 25 & 1 & $220 * 220$ & $1.75 h$ & Cut end angle $=90$ \\
\hline & $S-L 2-2$ & 25 & 1 & $220 * 220$ & $2.25 h$ & Cut end angle $=90$ \\
\hline \multirow{3}{*}{ Group (1) } & $R C 1$ & 25 & 2 & $150 * 300$ & without & Control specimen \\
\hline & $R 1-L 1-2$ & 25 & 2 & $150 * 300$ & $1.75 \mathrm{~h}$ & Cut end angle $=90$ \\
\hline & RI-L2-2 & 25 & 2 & $150 * 300$ & $2.25 h$ & Cut end angle $=90$ \\
\hline \multirow{2}{*}{ Group(3) } & $R C 2$ & 30 & 4 & $110 * 440$ & without & Control specimen \\
\hline & $R 2-L 1-2$ & 30 & 4 & $110 * 440$ & $1.75 \mathrm{~h}$ & Cut end angle $=90$ \\
\hline
\end{tabular}

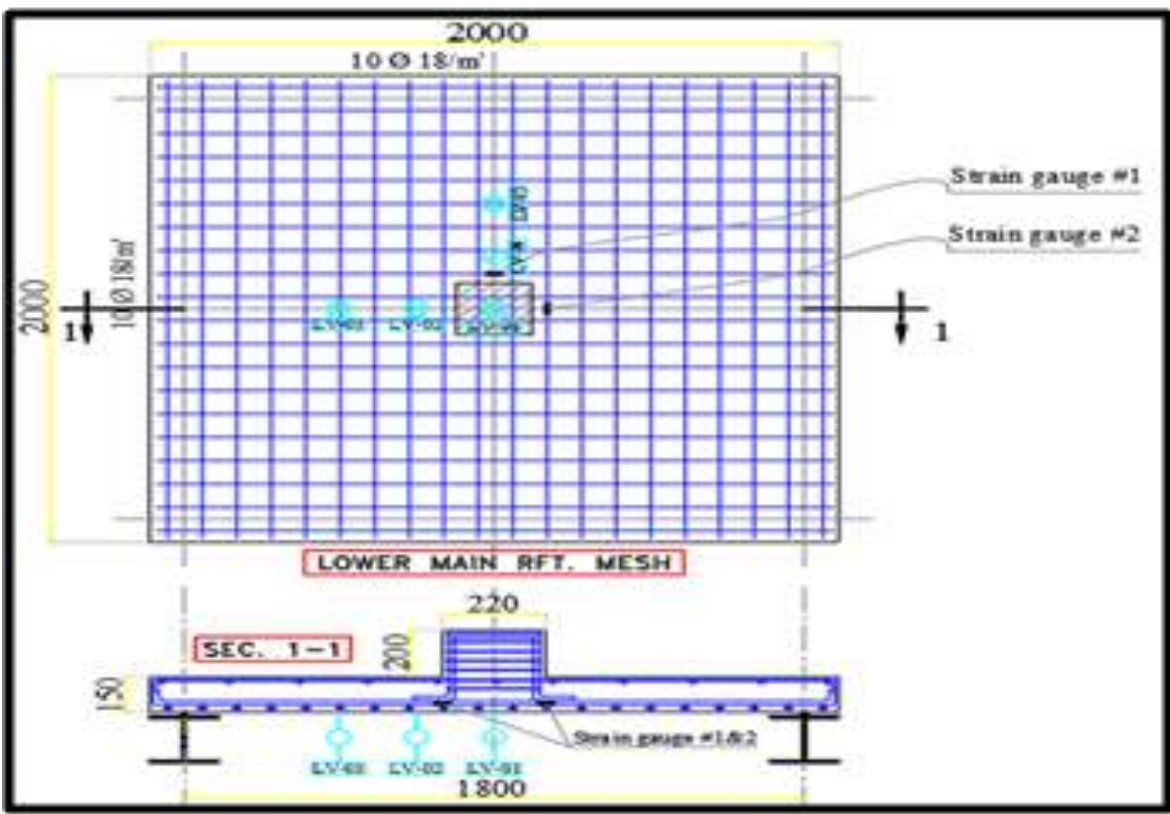

Fig 10: Location of installed LVDTs and strain gauges for Control (Without Shear Head) Flat Slab Specimens Which Connected by Square Columns. 

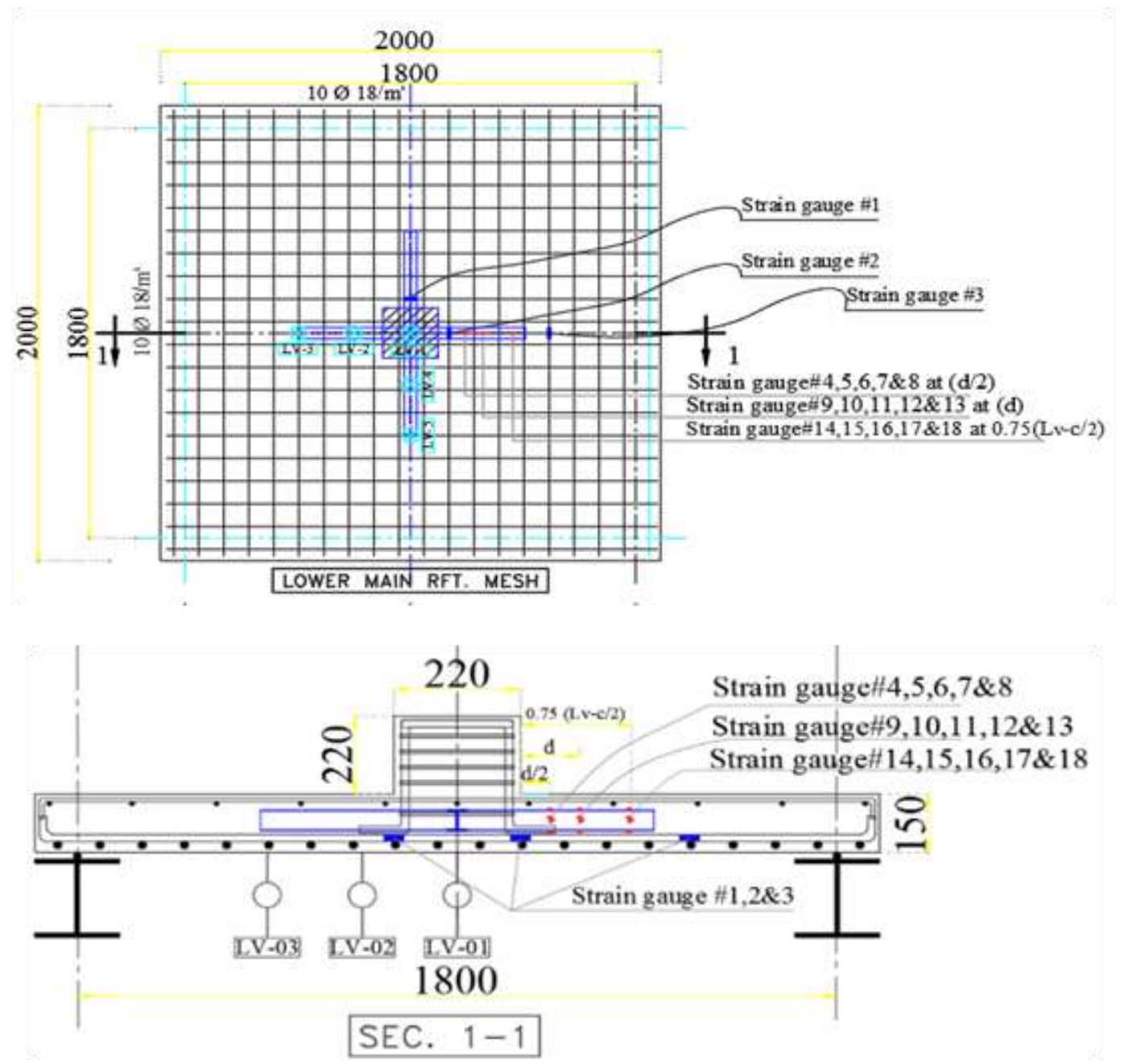

Fig11: Location of installed LVDTs and strain gauges for Flat Slab Specimens with Steel Shear Heads Which Connected by Square Columns.

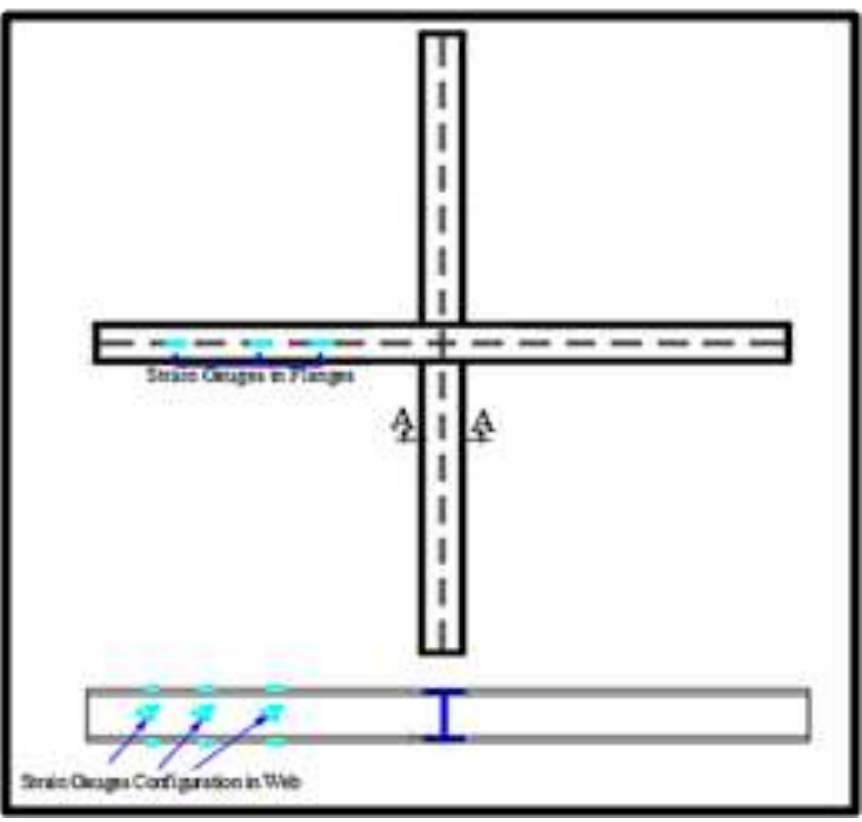

Fig12: Locations and Configuration of Strain Gauges in Web and Flanges of Steel Shear Head Sections. 


\subsection{Comparisons of Results between Experimental} and Numerical Analysis.

Table (6) describes and illustrates actual practical compressive strength, the maximum punching shear force, corresponding vertical deflection for experimental results
$(\mathrm{EXP})^{[12]}$ and finite element results which was extracted from (ANSYS) program.

The percentages between experimental punching shear force $\mathrm{V}_{\text {(EXP) }}$ and the maximum punching load from finite element program V(ANSYS) were also monitored. These ratios have also been calculated for vertical deflection in experimental test $\Delta_{(\mathrm{EXP})}$ and finite element program $\Delta_{\text {(ANSYS). }}$
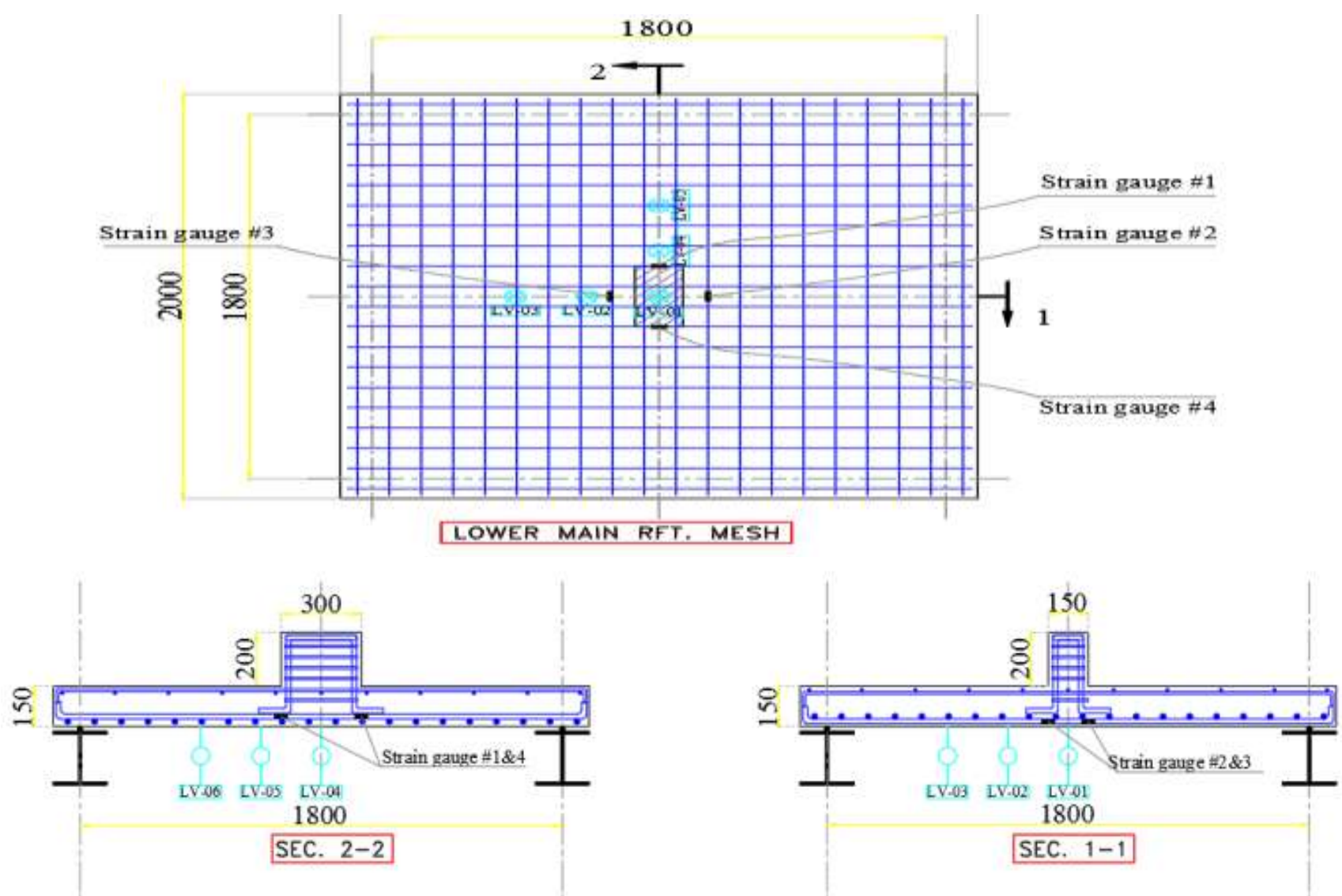

Fig 13: Location of installed LVDTs and strain gauges for All Flat Slab Specimens Which Connected by Rectangle Columns with aspect ratio $(2: 1)$.

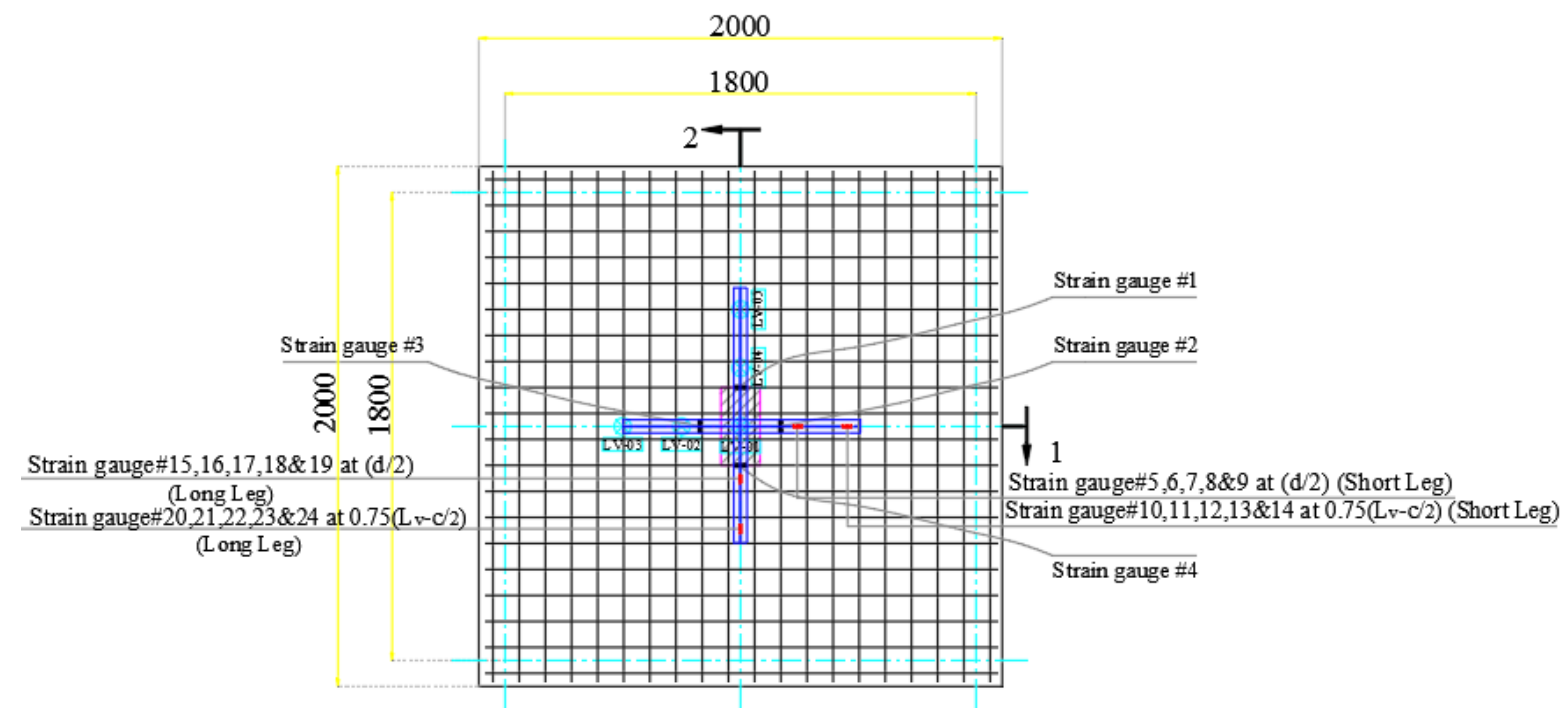

LOWER MAIN RFT. MESH 

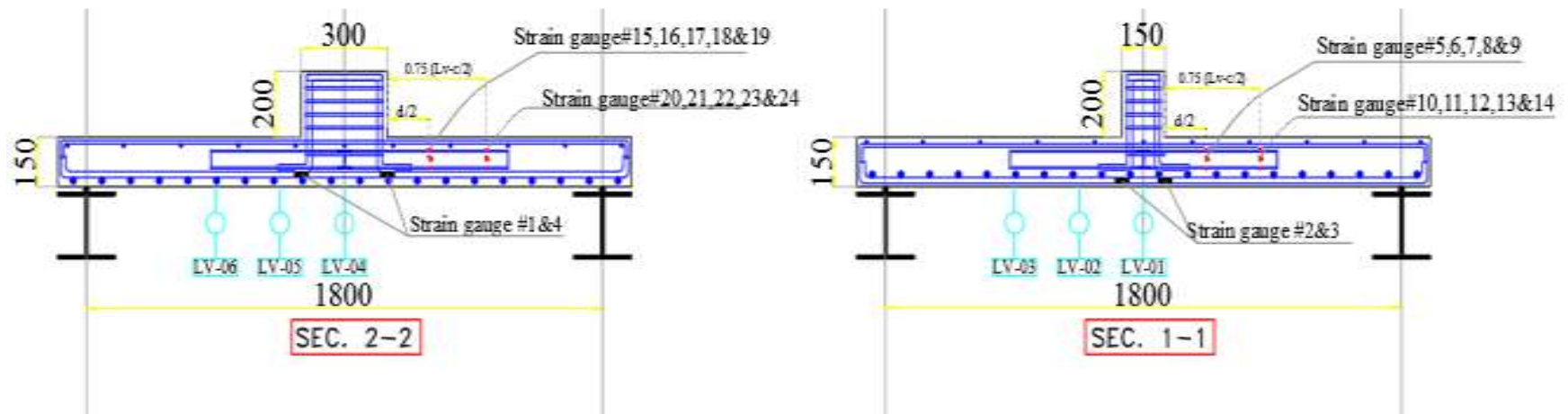

Fig 14: Location of installed LVDTs and strain gauges for Flat Slab Specimens with Steel Shear Heads Which Connected by Rectangle Columns with Aspect Ratio (2:1).

Table 6: Comparison of Flat Slab Finite Element Models with Corresponding Experimental Results.

\begin{tabular}{|c|c|c|c|c|c|c|c|c|c|}
\hline \multirow{2}{*}{$\begin{array}{l}\text { Flat } \\
\text { Slab } \\
\text { Model }\end{array}$} & \multirow{2}{*}{$\begin{array}{l}\text { ucf } \\
(\mathrm{MPa} \\
)\end{array}$} & \multirow{2}{*}{$\begin{array}{l}\text { Column } \\
\text { Dim. } \\
(\mathbf{m m})\end{array}$} & \multirow{2}{*}{$\begin{array}{l}\text { Aspe } \\
\text { ct } \\
\text { Ratio } \\
\left(\frac{a}{b}\right)\end{array}$} & \multicolumn{2}{|c|}{$\begin{array}{l}\text { EXP. } \\
\text { RESULTS }\end{array}$} & \multicolumn{2}{|c|}{$\begin{array}{l}\text { FEM. } \\
\text { RESULTS }\end{array}$} & \multicolumn{2}{|c|}{ DIFFERENCE } \\
\hline & & & & $\begin{array}{l}\mathbf{V}_{(\mathbf{E X P})} \\
(\mathbf{k N})\end{array}$ & $\begin{array}{l}\Delta_{(\mathbf{E X P})} \\
(\mathbf{m m})\end{array}$ & $\begin{array}{l}\mathbf{V}_{(\text {ANSYS }} \\
(\mathbf{k N})\end{array}$ & $\begin{array}{l}\Delta_{\text {(ANSYS }} \\
\text { (mm) }\end{array}$ & $\begin{array}{l}\mathbf{V}_{\text {(ANSYS }} \\
J_{(\text {EXP })} \\
\mathbf{V}_{(}\end{array}$ & $\begin{array}{l}\boldsymbol{\Delta}_{\text {(ANSYS }} \\
{ }_{)} / \boldsymbol{\Delta}_{\text {EXP. }}\end{array}$ \\
\hline SC & 25.00 & $(220 * 220)$ & 1.00 & 473.00 & 10.81 & 469.43 & 10.26 & 0.99 & 0.95 \\
\hline S-L1-2 & 25.00 & $(220 * 220)$ & 1.00 & 560.00 & 12.25 & 564.50 & 10.95 & 1.01 & 0.90 \\
\hline S-L2-2 & 25.00 & $(220 * 220)$ & 1.00 & 580.00 & 12.50 & 586.00 & 11.55 & 1.02 & 0.93 \\
\hline RC1 & 25.00 & $(150 * 300)$ & 2.00 & 468.00 & 11.20 & 493.00 & 10.35 & 1.05 & 0.92 \\
\hline $\begin{array}{l}\text { R1-L1- } \\
2\end{array}$ & 25.00 & $(150 * 300)$ & 2.00 & 557.5 & 12.50 & 562.80 & 11.95 & 1.01 & 0.96 \\
\hline $\begin{array}{l}\text { R1-L2- } \\
2\end{array}$ & 25.00 & $(150 * 300)$ & 2.00 & 582.00 & 13.20 & 584.00 & 12.35 & 1.01 & 0.94 \\
\hline RC2 & 25.00 & $(110 * 440)$ & 4.00 & -------- & $\begin{array}{l}------ \\
-\end{array}$ & 507.60 & 9.70 & $\begin{array}{l}-------- \\
-\end{array}$ & \\
\hline RC2 & 30.00 & $(110 * 440)$ & 4.00 & 556.00 & 11.60 & 559.00 & 10.60 & 1.01 & 0.92 \\
\hline $\begin{array}{l}\text { R2-L1- } \\
2\end{array}$ & 25.00 & $(110 * 440)$ & 4.00 & -------- & ------- & 585.40 & 11.55 & --------- & $\begin{array}{l}-------- \\
-\end{array}$ \\
\hline $\begin{array}{l}\text { R2-L1- } \\
2\end{array}$ & 30.00 & $(110 * 440)$ & 4.00 & 655.90 & 12.90 & 650.70 & 12.70 & 0.99 & 0.98 \\
\hline
\end{tabular}

This table shows that the difference in punching loads between experimental and numerical results which does not exceed $\pm 5 \%$.but regarding for vertical deflection, the difference was $\pm 10 \%$.

1. To study the effect of changing column aspect ratio $(\mathrm{a} / \mathrm{b})$ from (2.00) to (4.00) for Control models (RC1) and (RC2):

$$
\frac{V_{(R C 2)[A N S Y S]}}{V_{(R C 1)[A N S Y S]}}=1.08
$$

The effect of changing column aspect ratio $(\mathrm{a} / \mathrm{b})$ from $(2.00)$ to (4.00) led to increasing punching shear capacity $8 \%$. This happened unexpectedly because, according to the different design codes, it provides for a decrease in the value of punching shear force whenever the column aspect ratio decreases. the reason for this is the increasing of punching shear perimeter due to increasing of column perimeter. Increasing punching shear perimeter overcome a decrease in column aspect ratio by $8 \%$.

2. To study the expected contribution of changing compressive strength (fcu) from $25 \mathrm{Mpa}$ to be $30 \mathrm{Mpa}$ for control model (RC2):

$$
\frac{V_{\left(R C 2_{-f c u}=30 M p a\right)[A N S Y S]}}{\left.V_{\left(R C 2_{-} f c u\right.}=25 M p a\right)[A N S Y S]}=1.10
$$

This means that contribution of increasing compressive strength of concrete equal to $10 \%$ in enhancement punching shear force. 
3. To study the effect of using steel shear head with length equal to $1.75 \mathrm{~h}$ on punching shear enhancement of flat slabs which connected by a rectangle column have a column aspect ratio $(4: 1)$ whether in experimental or numerical analysis:

$$
\frac{V_{\left(R 2 \_L 1 \_2\right)}}{V_{(R C 2)}}=1.18
$$

This confirms that steel shear heads enhanced punching shear capacity by $18 \%$ for different compressive strength of concrete where it is the same enhancement percentage for other models which connected by a different column aspect ratio in which using the same length of steel shear heads (1.75h). The proof is that if we divide the punching shear capacity of specimen (R1-L1-2) on the punching shear capacity of specimen ( $\mathrm{RC} 1)$ whether in experimental or numerical analysis:

$$
\frac{V_{\left(R 1 \_L 1 \_2\right)}}{V_{(R C 1)}}=1.18
$$

4. To study the effect of using steel shear head with length equal to $2.25 \mathrm{~h}$ on punching shear enhancement of flat slabs which connected by a rectangle column have a column aspect ratio (1:1) in experimental analysis:

$$
\frac{V_{\left(S_{-} L 2 \_2\right)}}{V_{(S C)}}=1.22
$$

5. To study the effect of using steel shear head with length equal to $2.25 \mathrm{~h}$ on punching shear enhancement of flat slabs which connected by a rectangle column have a column aspect ratio (2:1) whether in experimental or numerical analysis:

$$
\frac{V_{\left(R_{-} L 2 \_2\right)}}{V_{(R C 1)}}=1.24
$$

\subsection{Comparison between Cracking Pattern of FE}

\section{Model and Experimental Results}

Figures (15) to (22) show the crack pattern at the top and bottom of the flat slabs specimens in the experimental program in comparing with the crack pattern of the FE model (CRACK AND CRUSHING) which describe the cracks in the model due to tensile stresses. The following figures show almost matching with each other. In the flat slabs models reinforced with steel shear head, existence of flexural cracks is obtained in both of experimental and FE model. This means that, the behavior of specimens contained steel shear head sections improved from brittle punching failure to semi brittle (gnihcnuP/Flexural) failure.

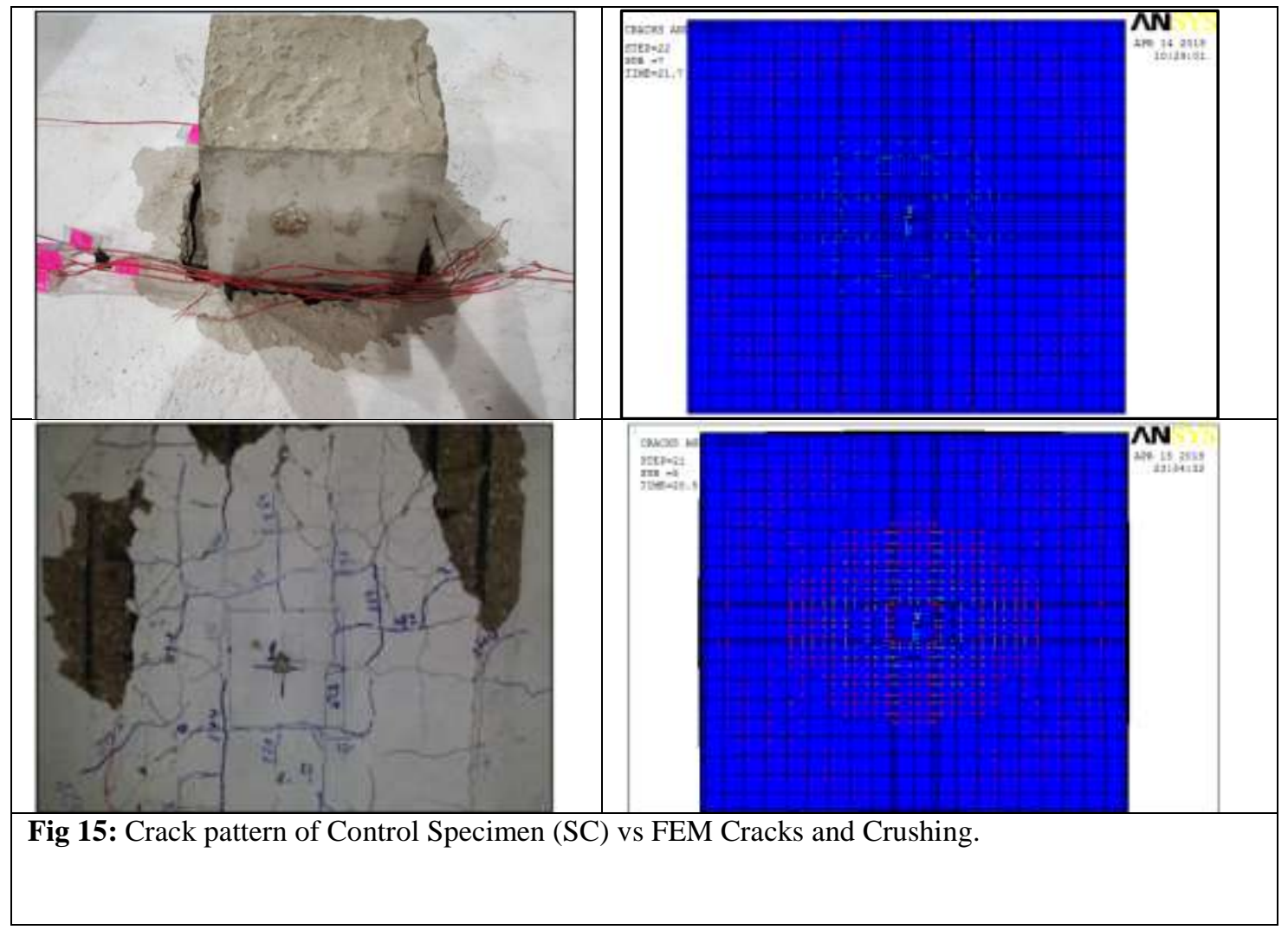




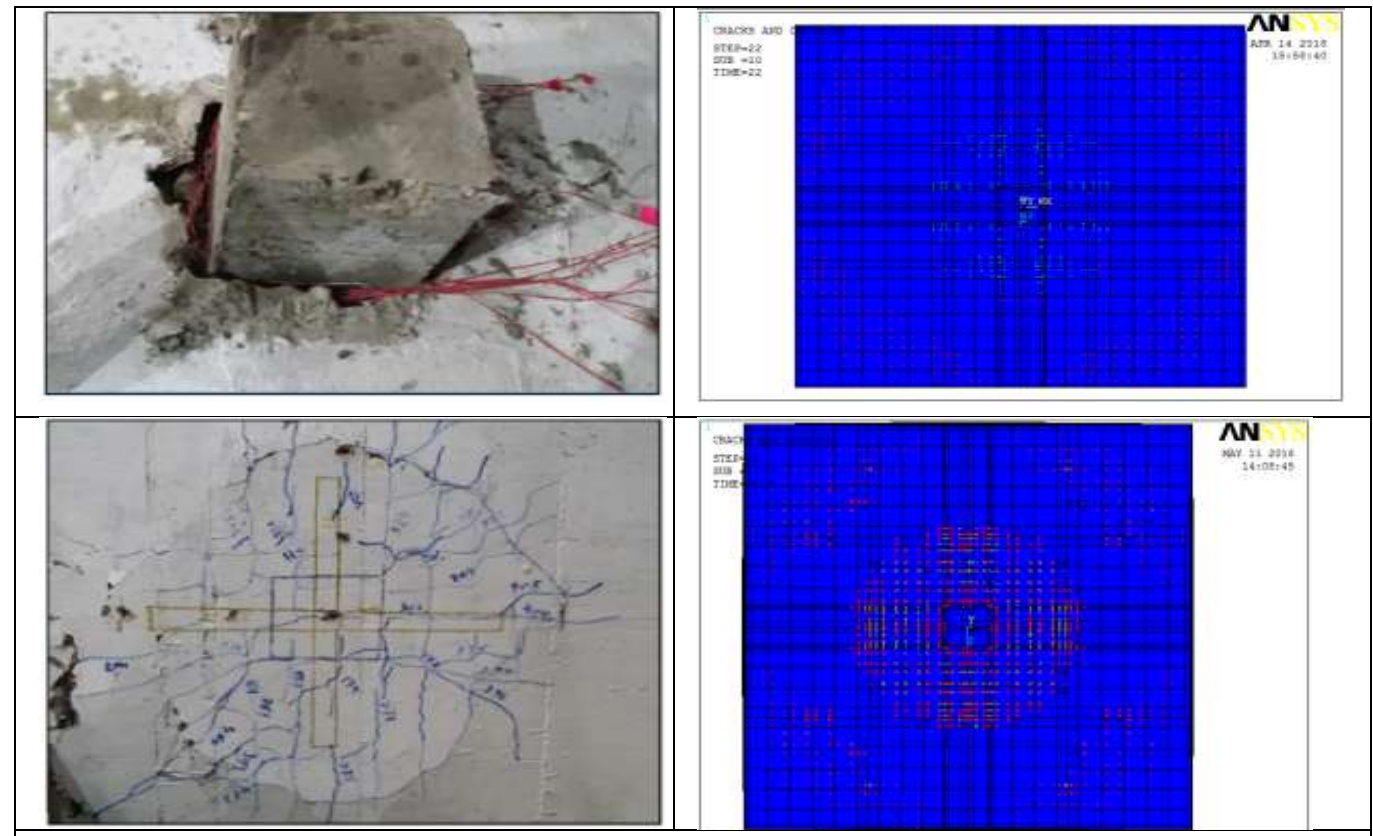

Fig 16: Crack pattern of Control Specimen (S-L1-2) vs FEM Cracks and Crushing.

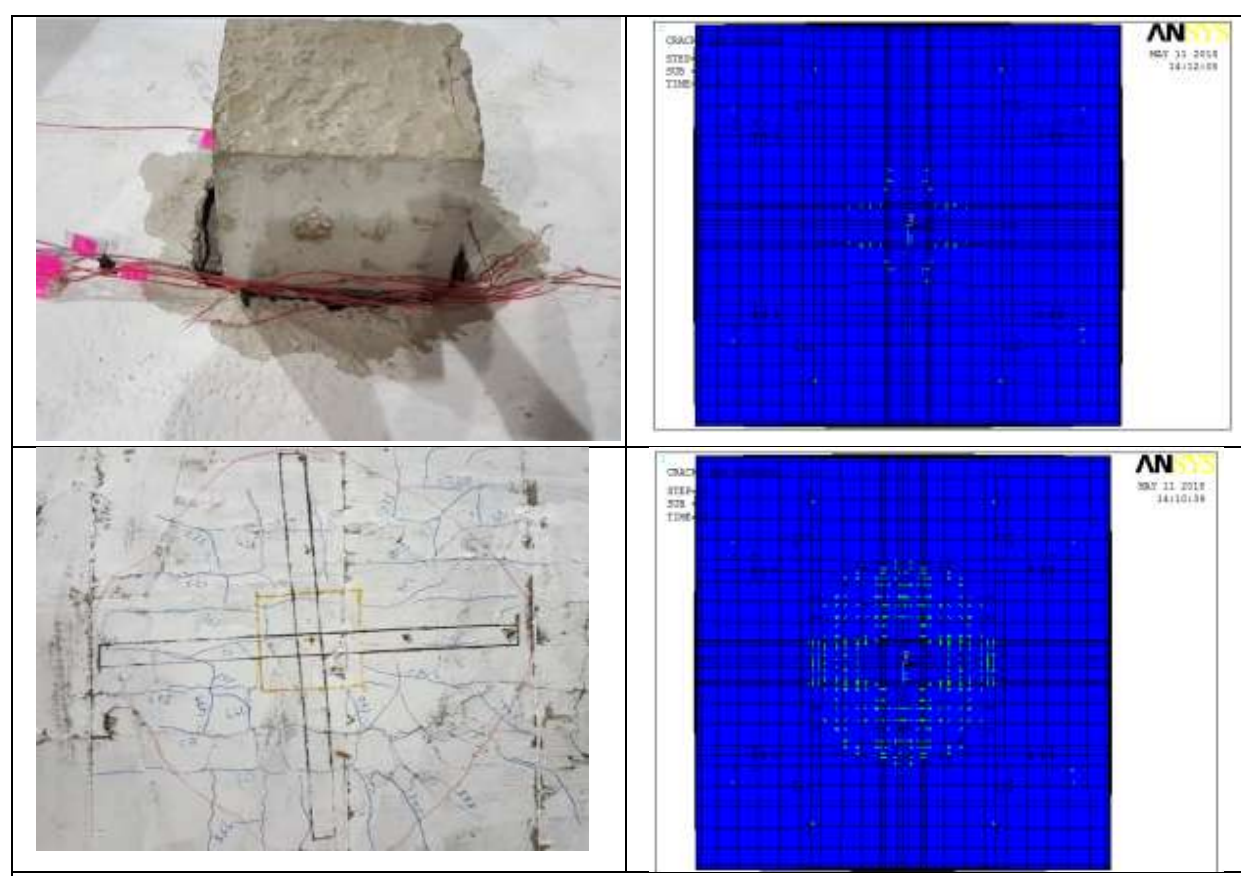

Fig 17: Crack pattern of Control Specimen (S-L2-2) vs FEM Cracks and Crushing. 

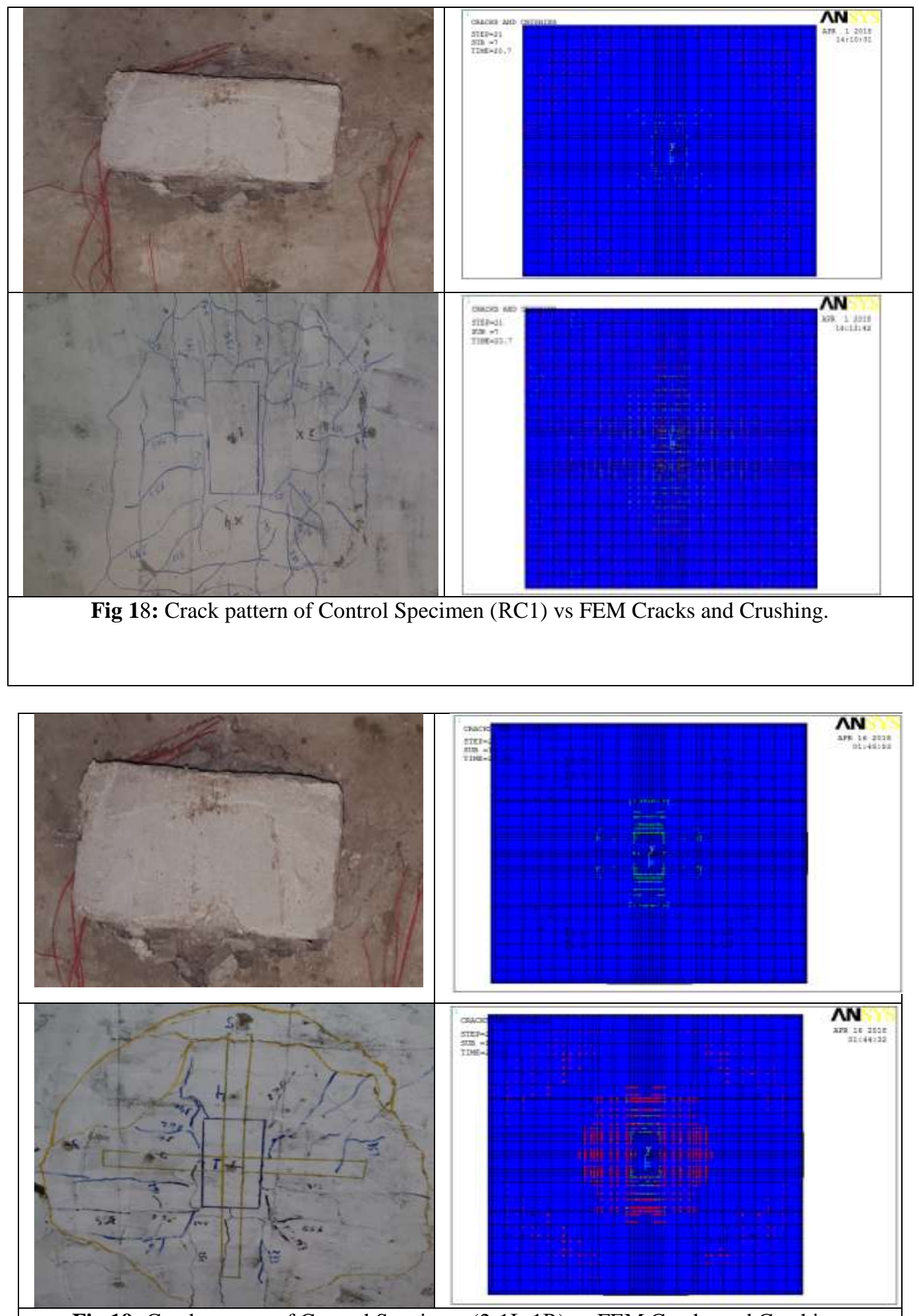

Fig 19: Crack pattern of Control Specimen (2-1L-1R) vs FEM Cracks and Crushing. 


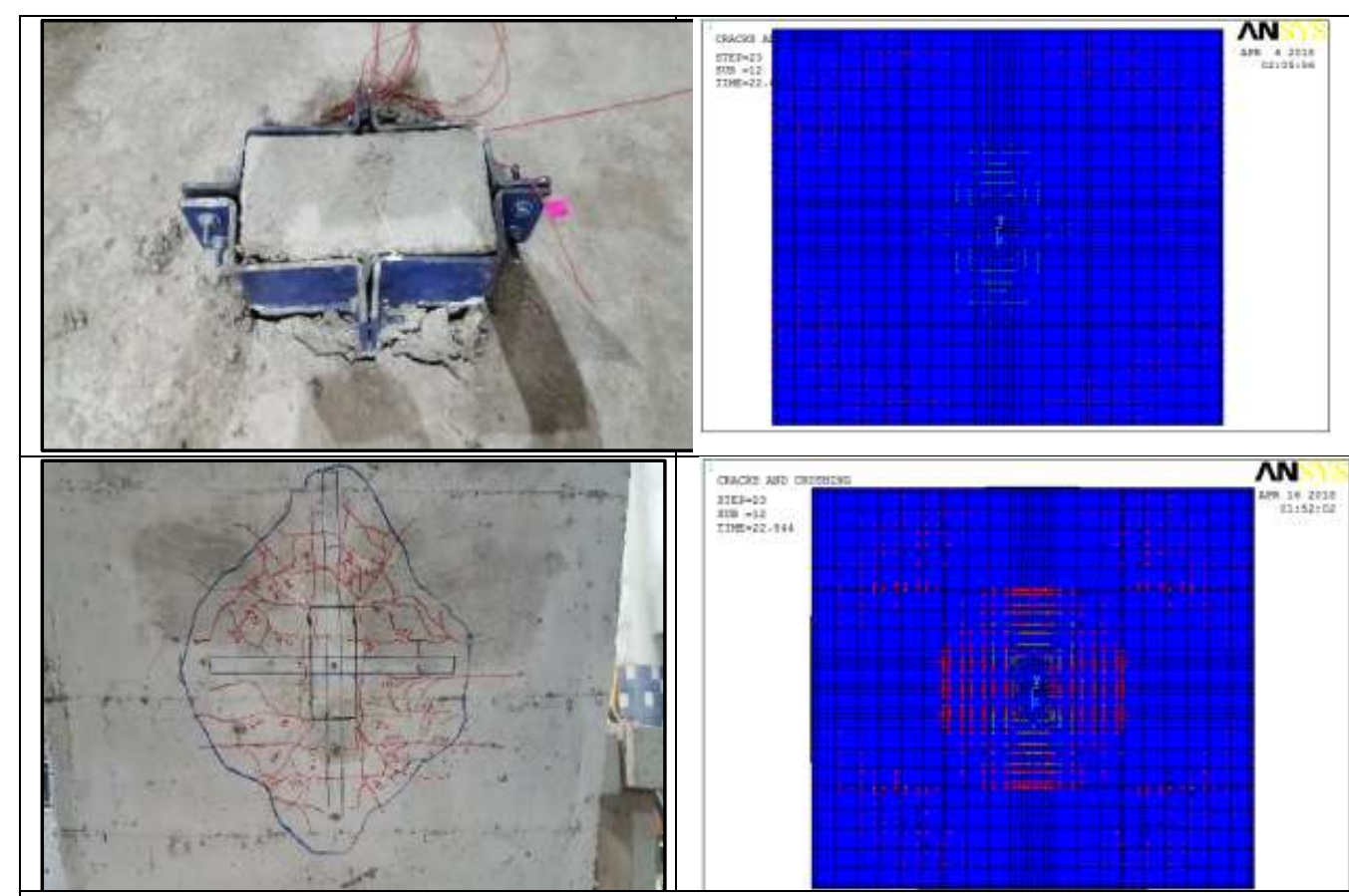

Fig 20: Crack pattern of Control Specimen (2-2L-1R) vs FEM Cracks and Crushing.

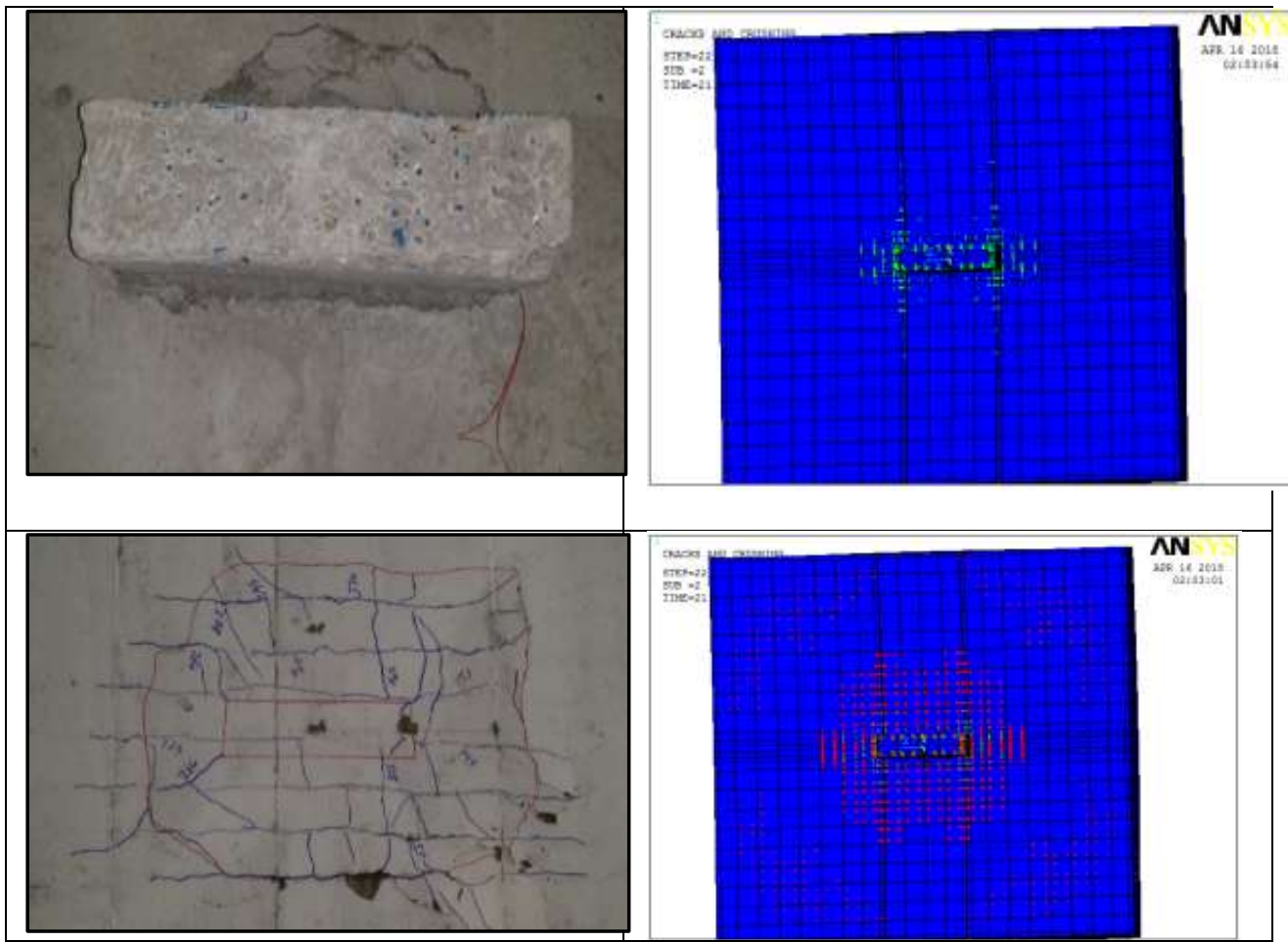

Fig 21: Crack pattern of Control Specimen (2CR) vs FEM Cracks and Crushing. 


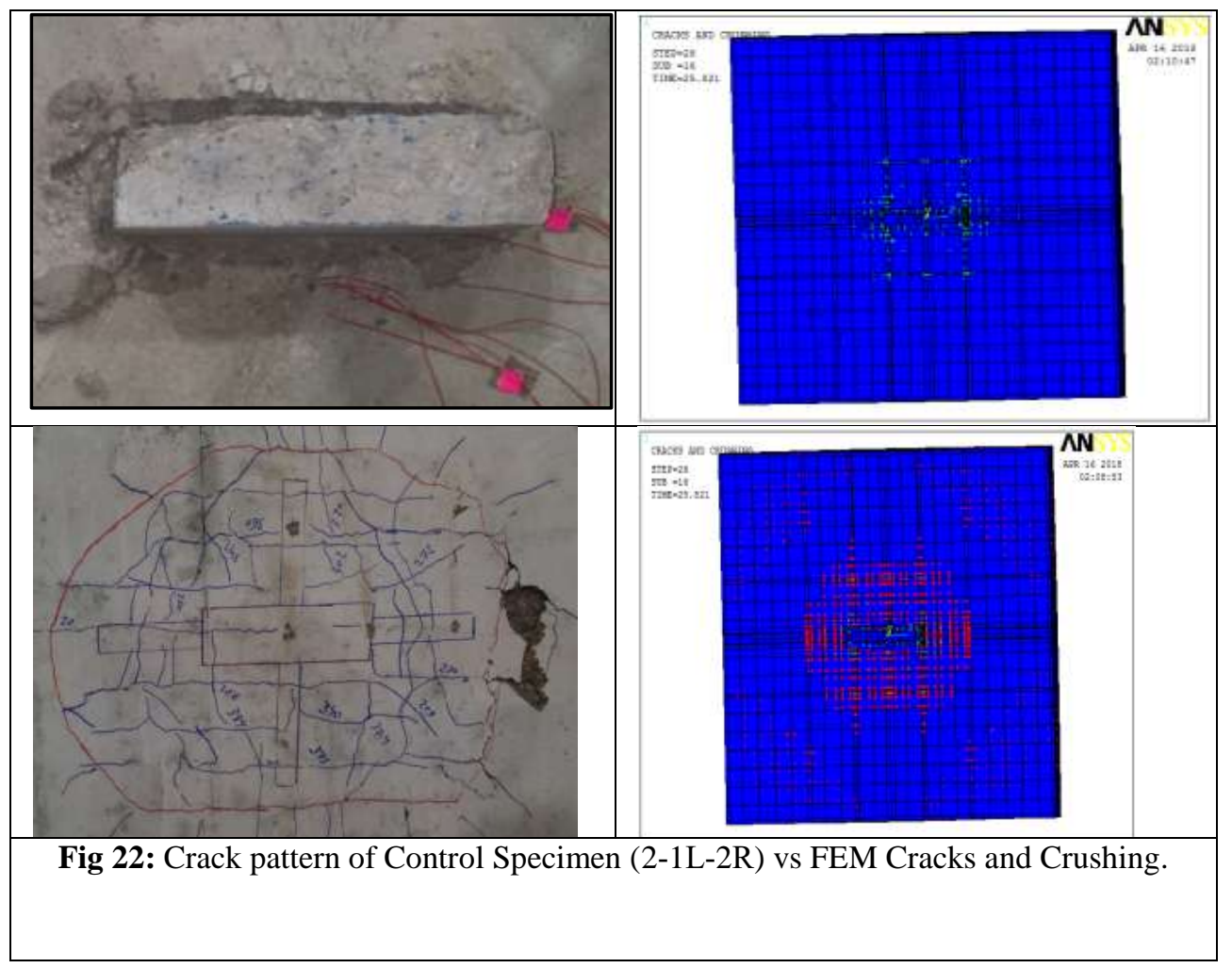

\subsection{Comparison Between Load-Displacement}

Responses in Both Experimental Study and Finite

\section{Element Model}

Figures from (23) to (30) illustrate the comparison between load-mid span deflections in experimental and FE model using ANSYS program.The differences between experimental and FF in terms of concrete deformations were considered due to boththe limitationsof concrete to deform with cracks and the crushing technique in ANSYS program.However,in general, both of FE and experimental responses have the same trend.

Due to laboratory conditions, the same two previous models (RC2) and (R2-L1-2) have been studied, but the value of a compressive strength for concrete (fcu) was changed from 25 MPa to be 30 MPaThe same was done in (ANSYS) program. This due to investigate the effect of both increasing perimeter of punching shear and increasing the compressive strength on punching shear resistance of slabs both separately. Figures (31) and (32) shows load-vertical deflection response for both slabs (RC2) and (R2-L1-2) in finite element modeling with a change in compressive strength.

\subsection{Comparison Between Contribution of Steel}

\section{Shear Heads in Both Experimental Study and}

\section{Finite Element Model}

Shear stresses was extracted from the "ANSYS" program as shown in Figure (33) and Figure (34) for slabs (S-L1-2) and (S-L2-2) respectively. the value of shear stress in the web was multiplied in the corresponding area to obtain the value of contribution for one leg of shear heads. These calculations were made at the critical section for punching shear which equal $(\mathrm{d} / 2)$ and $0.75\left(\mathrm{~L}_{\mathrm{v}}-\mathrm{c} / 2\right)$ from column face and at the final stage of loading. The contribution of shear heads was compared between the experimental and finite element program as shown in Figures (35) and (36) respectively sbals rof(S-L1-2) and (S-L2-2). 


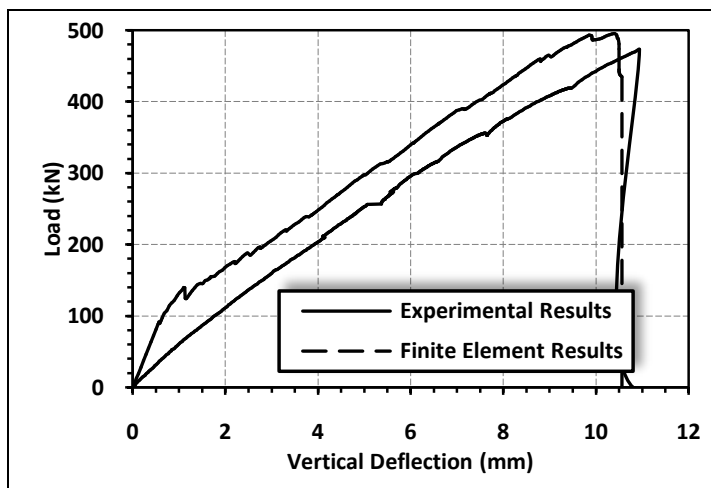

Fig 23: Load-Vertical Deflection Response for Slab (SC) in Both Experimental and FEM.

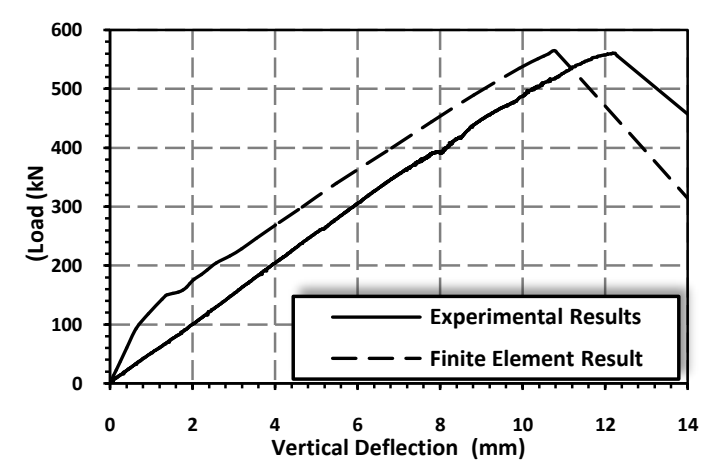

Fig 24: Load-Vertical Deflection Response for Slab(SL1-2) in Both Experimental and FEM.

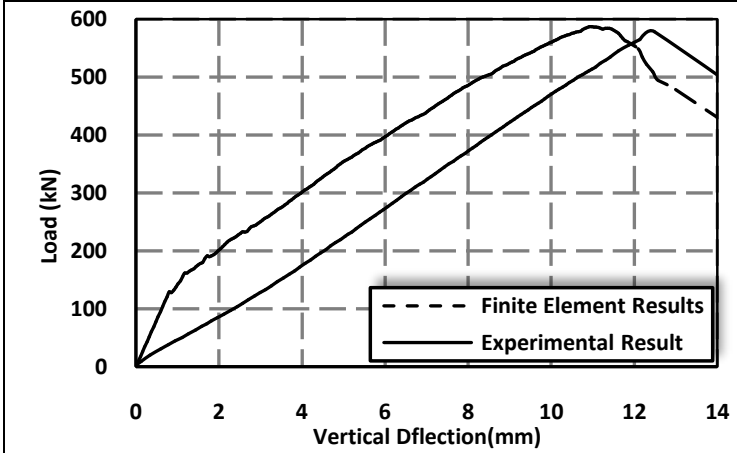

Fig 25: Load-Vertical Deflection Response for Slab(S-L2-2) in Both Experimental and FEM.

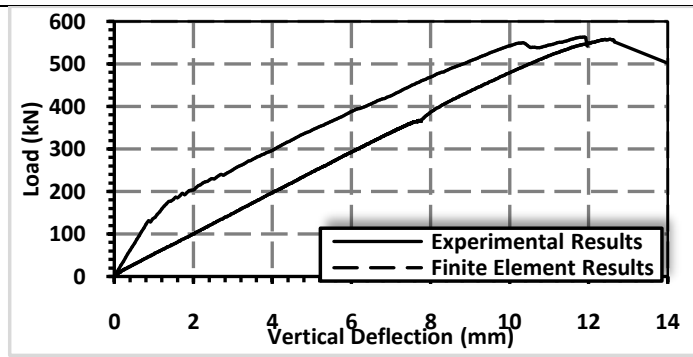

Fig 27: Load-Vertical Deflection Response for Slab(R1-L1-2) in Both Experimental and FEM.

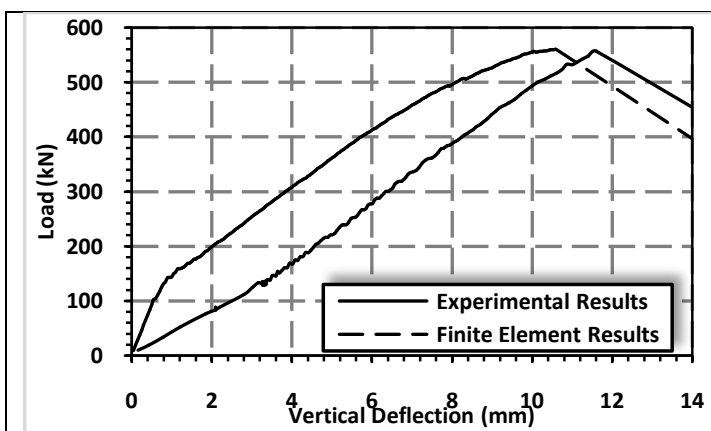

Fig 29: Load-Vertical Deflection Response for Slab(RC2) in Both Experimental and FEM.

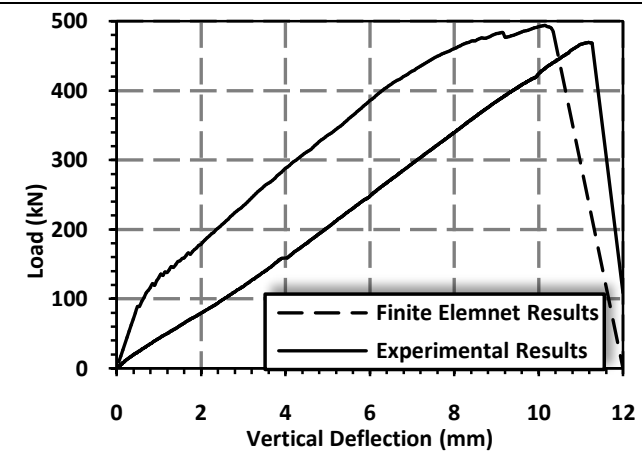

Fig 26: Load-Vertical Deflection Response for $\mathrm{Slab}(\mathrm{RC} 1)$ in Both Experimental and FEM.

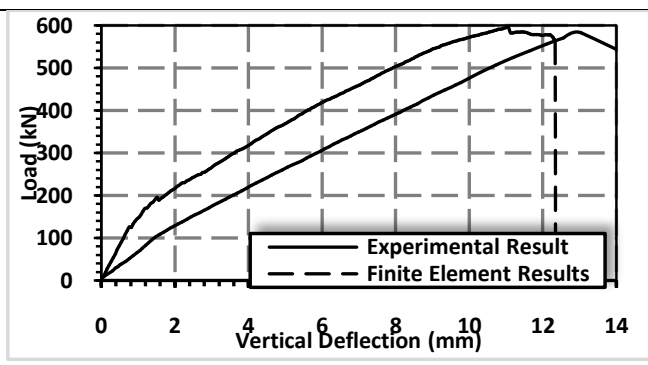

Fig 28:Load-Vertical Deflection Response for Slab(R1-L2-2) in Both Experimental and FEM.

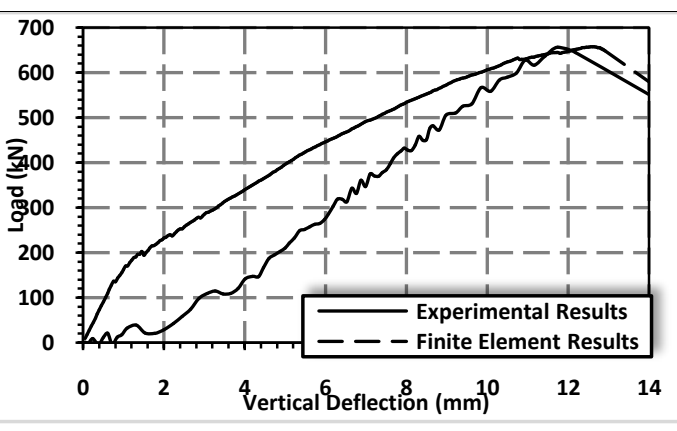

Fig 30: Load-Vertical Deflection Response for Slab (R2-L1-2) in Both Experimental and FEM. 


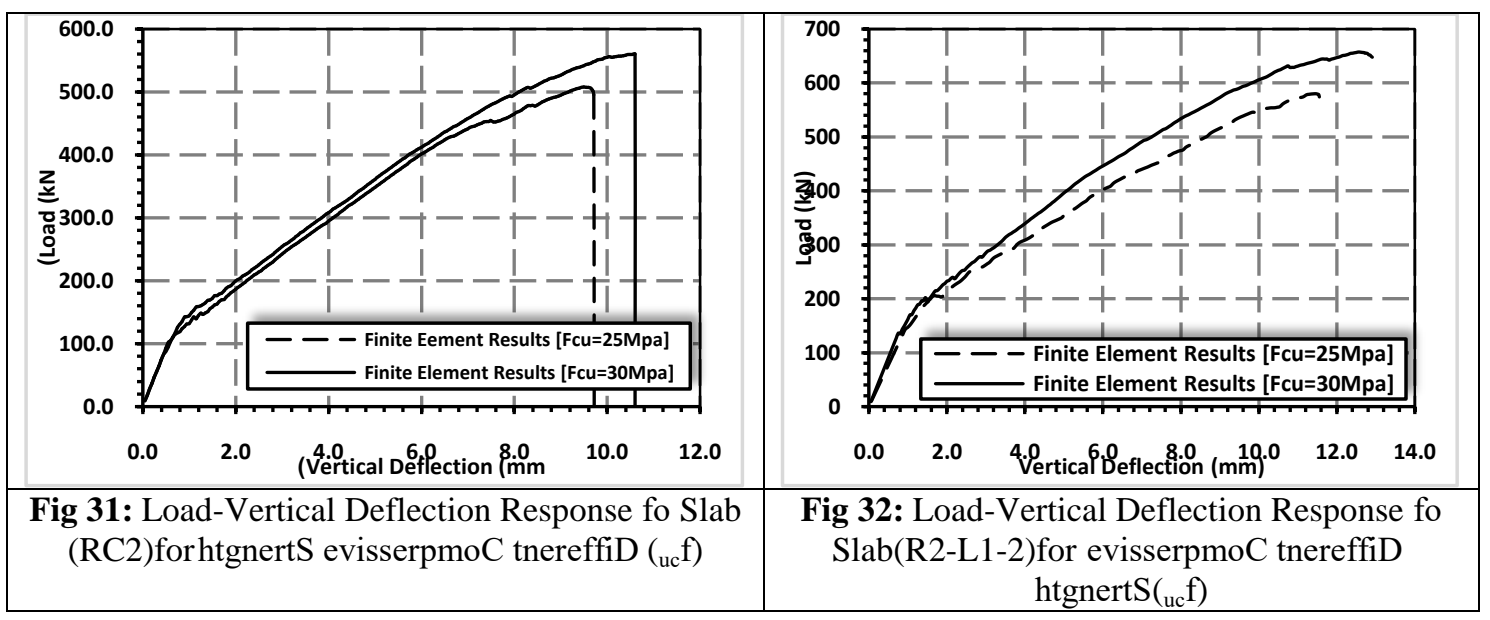

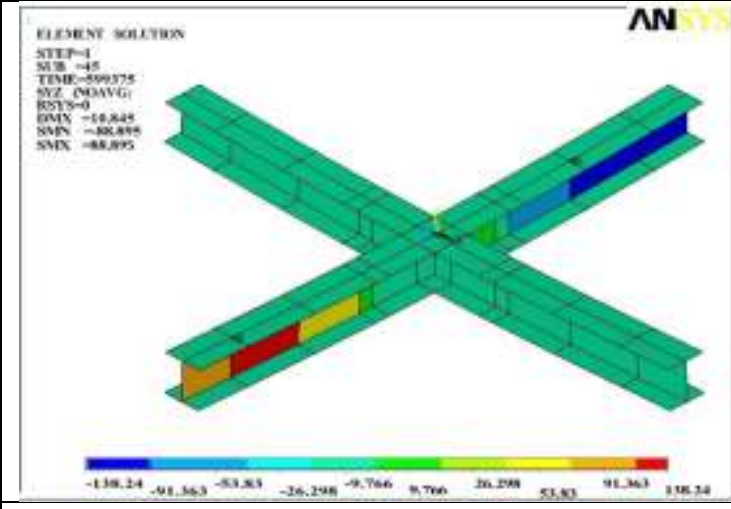

Fig 33: Shear Stresses in Web of Shear Head along its Length for Finite Element Model of Slab (S-L12).

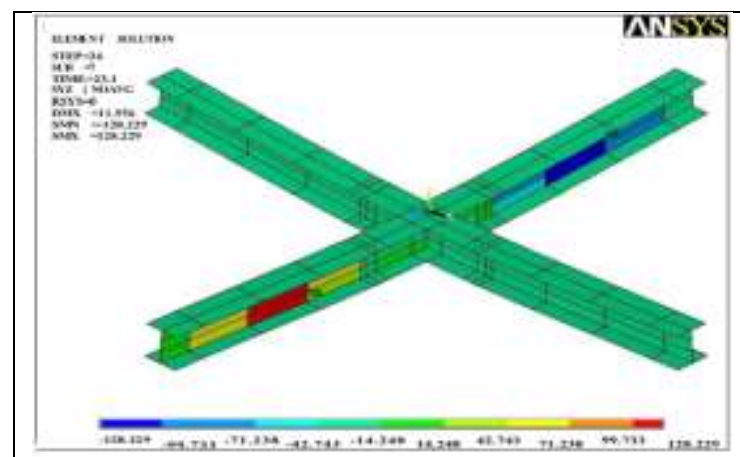

Fig 34: Shear Stresses in Web of Shear Head along its Length for Finite Element Model of Slab (S-L22).

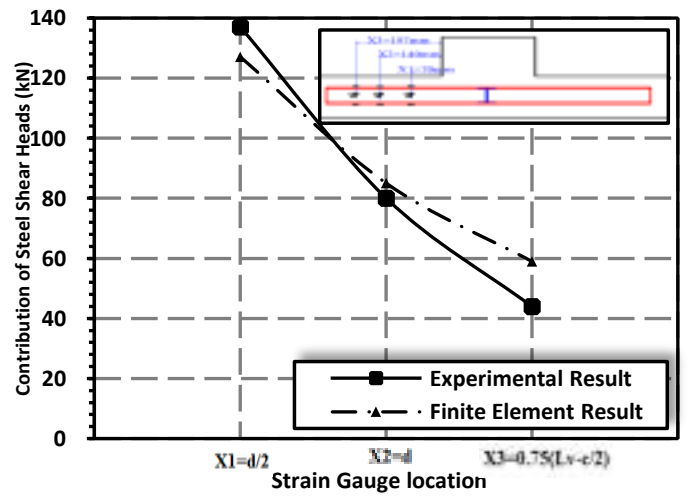

Fig 35:Contribution of Shear Heads at Different

Locations along its Length of Slab

(S-L1-2) for Both Experimental and FEM. 


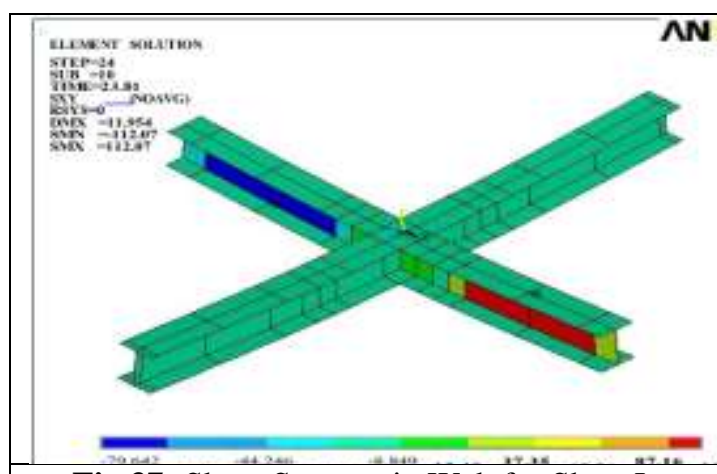

Fig 37: Shear Stresses in Web for Short Legs of Shear Head along its Length for Finite Element Model of Slab (R1-L1-2).

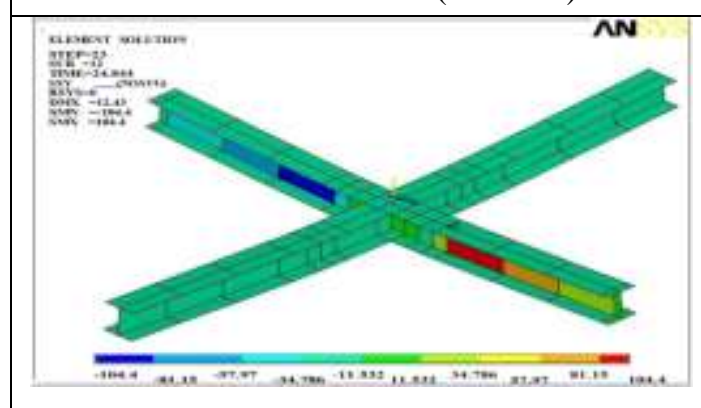

Fig 39: Shear Stresses in Web for trohS Legs of Shear Head along its Length for Finite Element Model of Slab (R1-L2-2).

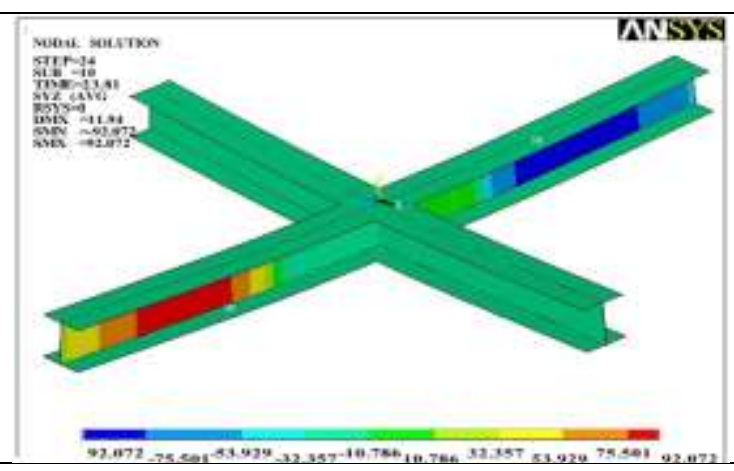

Fig 38: Shear Stresses in Web for Long Legs of Shear Head along its Length for Finite Element Model of Slab (R1-L1-2).

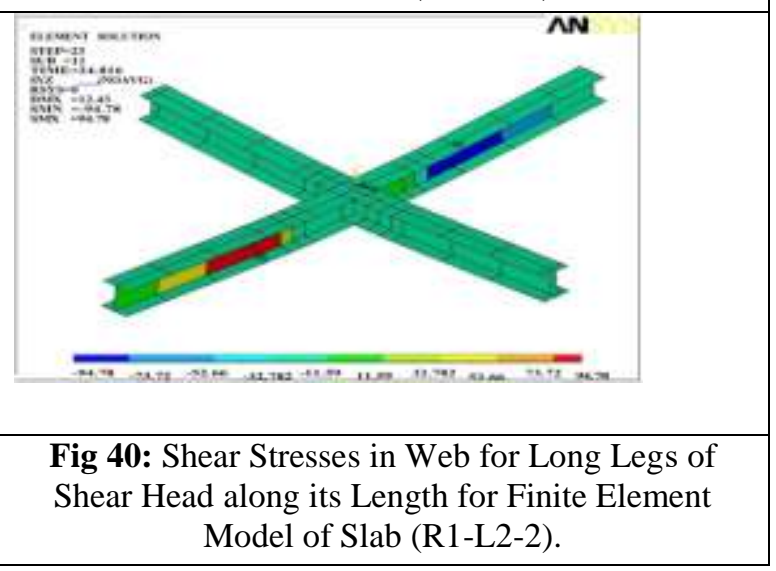

Fig 41: Total Contribution of Shear Heads at Different Locations along its Length of Slab (R1L1-2) for Both Experimental and FEM.

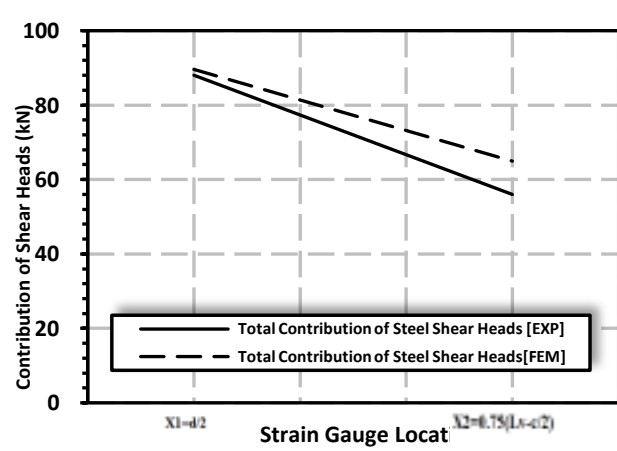

Fig 42: Total Contribution of Shear Heads at Different Locations along its Length of Slab (R1-L2-2) for Both Experimental and FEM.

Shear stresses were plotted for short and long legs in Figures (37), (38) and Figures (39), (40) for short and long legs of slabs (R1-L1-2) and (R1-L2-2) respectively.Total contribution of steel shear heads also plotted in Figures (41) and (42) for slabs(R1-L1-2) and (R1-L2-2) respectively.Figures (43) and (44) shows shear stresses in webs for short and long legs respectively of slab (R2-L1-2). 


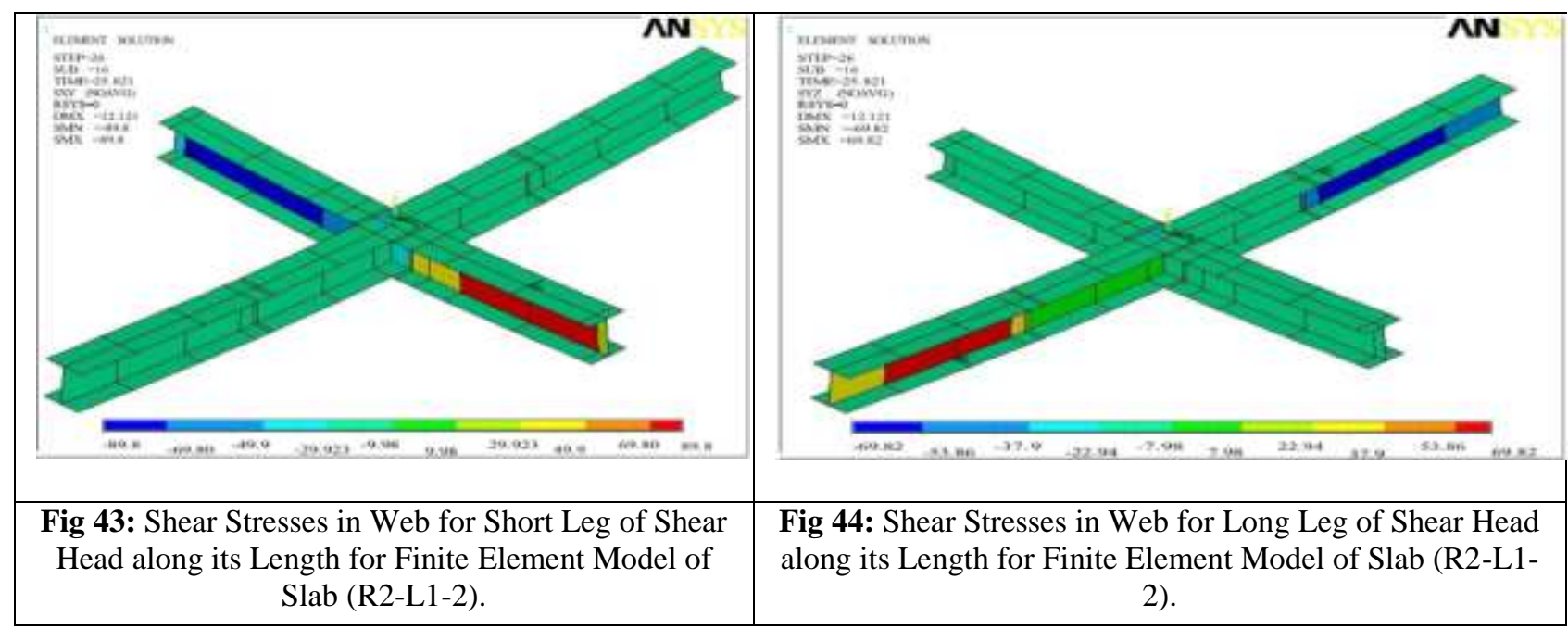

Figure (45) shows total contribution of steel shear heads for short and long column face at different locations from column face of slab (R2-L1-2).

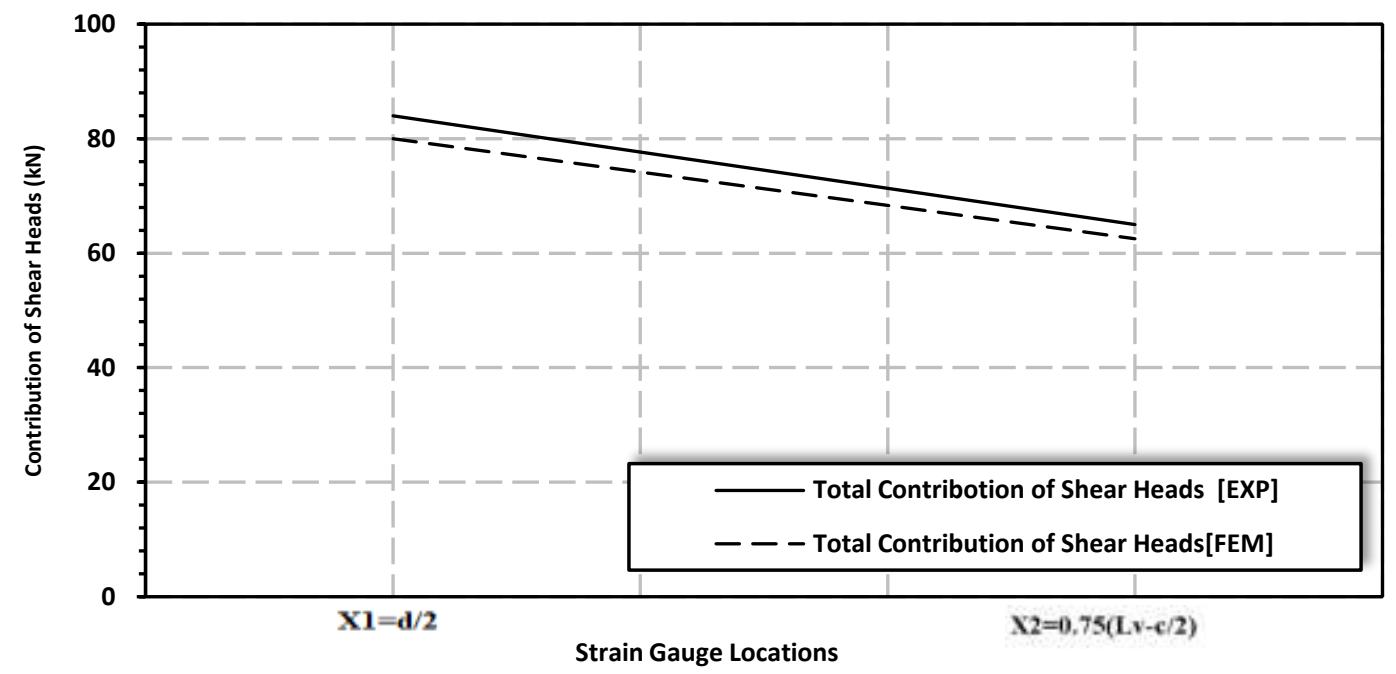

Fig 45: Total Contribution of Shear Heads at Different Locations along its Length of Slab (R2-L1-2) for Both Experimental and FEM.

It is not a requirement that the shear heads bear the complete difference for punching load improvement, depending on that the shear heads improve the concrete resistance from the beginning of loading. The effect of the tensile flange of shear heads delays the first crack in the concrete. As knowing, the improvement of the slab behavior in bending resistance through compression and tension flanges improves the behavior of the slab in the shear. This improvement result of increasing the effect of the compression zone in concrete.

Table (7) was made in an attempt to find the values of the net contribution of the concrete $\left(\mathrm{V}_{\mathrm{c} 1)}\right.$ and find the adjusted modified improvement values on concrete $\left(\mathrm{V}_{\mathrm{c} 2}\right)$ for each tested specimen. The percentage for contribution of steel shear heads $\left(\mathrm{V}_{\mathrm{s}}\right)$ according to total contribution of concrete displayed in Table (7). Also the percentage of modified concrete resistance $\left(\mathrm{V}_{\mathrm{c} 2}\right)$ according to total contribution of concrete $\left(\mathrm{V}_{\mathrm{c}}\right)$ also displayed in the same table. 
Table 7: Results Summary of all Tested Slabs

\begin{tabular}{|c|c|c|c|c|c|c|}
\hline \multirow{2}{*}{$\begin{array}{c}\text { Specimen } \\
\text { Code }\end{array}$} & \multirow{2}{*}{$V_{u}(\mathrm{kN})$} & \multicolumn{2}{|c|}{$V_{c}(\mathrm{kN})$} & \multirow{2}{*}{$V_{S}(\mathrm{kN})$} & \multirow{2}{*}{$\frac{V_{s}}{V_{c}}(\%)$} & \multirow{2}{*}{$\frac{V_{c 2}}{V_{c}}(\%)$} \\
\hline & & $V_{c 1}(\mathrm{kN})$ & $V_{c 2}(\mathrm{kN})$ & & & \\
\hline SC & 473.00 & 473.00 & & & & \\
\hline S-L1-2 & 556.00 & 473.00 & 19.00 & 64.00 & 13.00 & 3.80 \\
\hline S-L2-2 & 580.00 & 473.00 & 40.00 & 67.00 & 13.00 & 7.80 \\
\hline $\mathrm{RC} 1$ & 468.00 & 468.00 & $\bar{\square}$ & & & \\
\hline R1-L1-2 & 557.00 & 468.00 & 18.00 & 71.00 & 14.60 & 3.70 \\
\hline R1-L2-2 & 582.00 & 468 & 39.00 & 75.00 & 14.80 & 7.70 \\
\hline $\mathrm{RC} 2$ & 556.50 & 556.60 & $\bar{L}$ & & & \\
\hline R2-L1-2 & 655.90 & 556.60 & 26.30 & 73.00 & 13.20 & 4.70 \\
\hline
\end{tabular}

\section{CONCLUSION}

- $\quad$ Efficiency of the FE modelin simulationof reinforced concrete flat slabs with shear Heads, was proved from compression FE model results with experimental results.

- FE model gives crack patterns almost similar to the experimental ones and the same trend of the loaddeflection response.

- Flat slabs with steel shear heads enhanced the behaviorand mode of failureof slabs to be semi brittle failure (flexural/punching) instead of brittle failure (pure punching) in slabs without shear heads.

- Flat slab specimens which connected by a square column with aspect ratio (1:1) give almost same results with other specimens connected by a rectangle column with aspect ratio equal (2:1).

- Steel shear heads enhanced punching shear capacity by $18 \%$ for different compressive strength of concrete where it is the same enhancement percentage for other models which connected by a different column aspect ratio in which using the same length of steel shear heads (1.75h).

- Steel shear head with length equal to $(2.25 \mathrm{~h})$ enhanced punching shear of flat slabs which connected by a rectangle column have a column aspect ratio (1:1) by $22 \%$.

- $\quad$ steel shear head with length equal to $(2.25 \mathrm{~h})$ enhanced punching shear of flat slabs which connected by a rectangle column have a column aspect ratio $(2: 1)$ by $24 \%$.

- The effect of changing column aspect ratio $(\mathrm{a} / \mathrm{b})$ from (2.00) to (4.00) led to increasing punching shear capacity by $8 \%$. This happened unexpectedly because, according to the different design codes, it provides for a decrease in the value of punching shear force whenever the column aspect ratio decreases. the reason for this is the increasing of punching shear perimeter due to increasing of column perimeter. Increasing punching shear perimeter overcome a decrease in column aspect ratio by $8 \%$.

- The expected contribution of changing compressive strength $\left(\mathrm{f}_{\mathrm{cu}}\right)$ from $25 \mathrm{Mpa}$ to be $30 \mathrm{Mpa}$ for control model (RC2) is equal to $10 \%$.

\section{REFERENCES}

[1] M. M. ywadaB:" talF fO raehS gnihcnuP gnitsise R sdaeH raehS yB sbalS" Ph.D. thesis, Ani-smahS University, Faculty of Engineering, Civil Engineering Department 2018, under revision.

[2] ACI Committee 318. 2014 "Commentary on Building Code Requirements for structural Concrete (ACI 318 R-14)." American Concrete Institute. Farmington Hills, MI,48331.

[3] ACI Committee 318, (1977), "Building Code Requirements for Reinforced Concrete (ACI 31877)," American Concrete Institute, Farmington Hills, MI, $103 \mathrm{pp}$.

[4] CORLEY, W. G. \& HAWKINS, N. M. (1968) Shear head Reinforcement for slabs. ACI Journal, October 1968, 811-824.

[5] Hawkins, N. M., and Corley, W. G., (1974), "Moment Transfer to Columns in Slabs with Shear Head Reinforcement," Shear in Reinforced Concrete, SP-42, American Concrete Institute, Farmington Hills, MI, Jan., pp. 847-880.

[6] ACI 318M-2005. Building code requirements for structural concrete and commentary. Committee 318, Farmington Hills, Michigan, USA; (2005). 430pp.

[7] ACI Committee 318, 2011, "Building Code Requirements for Structural Concrete (ACI 318-11) and Commentary," American Concrete Institute, Farmington Hills, MI, 503 pp.

[8] Jin-Won Kim, Cheol-Ho Lee, and Thomas H.-K. Kang,Title No. 111-S52, ACI Structural Journal/May-June 2014

[9] M.A. Eder, R.L. Volluma, A.Y. Elghazouli, T. Abdel-Fattah-Engineering Structures 32 (2010) 3911-39242010 -Elsevier Ltd.

[10] Finite Element Program [ANSYS12.0].

[11] K.J.William, E.P. Warnke "CONSTITUTIVE MODEL FOR THE TRIAXIAL BEHAVIOUR OF CONCRETE" University of Stuttgart (1974).

[12] Mohamed Badawy, etc. "Punching Shear Resistance of Flat Slabs By Shear Heads." International Journal Of Engineering Research And Development, e-ISSN: 2278-067X, p-ISSN: 2278-800X, www.ijerd.com Volume 13, Issue 11 (November 2017), PP.47-66 